\title{
Representation of Two-Phase Flow in the Vicinity of the Repository in the 1996 Performance Assessment for the Waste Isolation Pilot Plant
}

\author{
P. Vaughn ${ }^{a}$, J.E. Bean ${ }^{b}$, J.C. Heltonc, M.E. Lord ${ }^{a}$, R.J. MacKinnon ${ }^{a}$, J.D. Schreiber ${ }^{a}$ \\ ${ }^{a}$ Sandia National Laboratories, Albuquerque, NM 87185; bNew Mexico Engineering Research Institure, \\ Albuquerque, NM1 87106; Department of Mathematics, Arizona State University, Tempe, AZ 85287
}

\begin{abstract}
The following topics related to the representation of two-phase (i.e., gas and brine) flow in the vicinity of the repository in the 1996 performance assessment (PA) for the Waste Isolation Pilot Plant (WIPP) are discussed: (i) system of nonlinear parial differential equations used to model rwo-phase flow, (ii) incorporation of repository shafis into model (iii) creep closure of repository, (iv) interbed fracturing, (v) gas generation, (vi) capillary action in waste, (rii) borehole model, (viii) numerical solution. and (ix) gas and brine flow across specified boundaries. Twophase flow calculations are a central part of the 1996 WIPP PA and supply results that are subsequently used in the calculation of releases to the surface at the time of a drilling intrusion (i.e., spallings, direct brine releases) and longterm releases due to radionuclide transport by flowing groundwater.
\end{abstract}

Key Words: BRAGFLO, compliance certification application, performance assessment, radioactive waste, repository, transuranic waste, two-phase flow, Waste Isolation Pilot Plant

Please send page proof to:

Jon C. Helton

Department 6848. MS 0779

Sandia National Laboratories

Albuquerque. NM 87185-0779, LSA

Phone: $505-284-4808$

Fax: 505-844-2348

email: jchelto(a.sandia.gov 


\section{DISCLAIMER}

This report was prepared as an account of work sponsored by an agency of the United States Government. Neither the United States Government nor any agency thereof, nor any of their employees, make any warranty, express or implied, or assumes any legal liability or responsibility for the accuracy, completeness, or usefulness of any information, apparatus, product, or process disclosed, or represents that its use would not infringe privately owned rights. Reference herein to any specific commercial product, process, or service by trade name, trademark, manufacturer, or otherwise does not necessarily constitute or imply its endorsement, recommendation, or favoring by the United States Government or any agency thereof. The views and opinions of authors expressed herein do not necessarily state or reflect those of the United States Government or any agency thereof. 


\section{DISCLAIMER}

Portions of this document may be illegible in electronic image products. Images are produced from the best available original document. 


\section{Introduction}

At a conceptual level, the 1996 performance assessment (PA) for the Waste Isolation Pilot Plant (WIPP) is underlain by three entities (EN1, EN2, EN3): EN1, a probabilistic characterization of the likelihood of different futures occurring at the WIPP site over the next $10,000 \mathrm{yr}$; EN2, a procedure for estimating the radionuclide releases to the accessible environment associated with each of the possible futures that could occur at the WIPP site over the next $10,000 \mathrm{yr}$; and EN3, a probabilistic characterization of the uncertainty in the parameters used in the definitions of EN1 and EN2 (Sect. 2, Ref. 1). The model for two-phase flow in the vicinity of the repository constitutes part of the second entity and is the primary focus of this article.

When viewed formally, EN2 is defined by a function $f$ of the form

$$
\begin{aligned}
& f\left(\mathbf{x}_{s t}\right)=f_{C}\left(\mathbf{x}_{s t}\right)+f_{S P}\left[\mathbf{x}_{s t}, f_{B}\left(\mathbf{x}_{s t}\right)\right]+f_{D B R}\left\{\mathbf{x}_{s t}, f_{S P}\left[\mathbf{x}_{s t}, f_{B}\left(\mathbf{x}_{s t}\right)\right], f_{B}\left(\mathbf{x}_{s t}\right)\right\}
\end{aligned}
$$

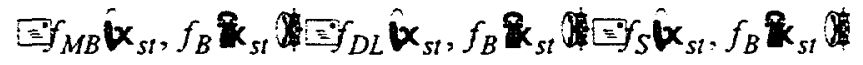

$$
\begin{aligned}
& +f_{S-T}\left\{\mathbf{x}_{s t, 0}, f_{S-F}\left(\mathbf{x}_{s t, 0}\right), f_{N-P}\left[\mathbf{x}_{s l}, f_{B}\left(\mathbf{x}_{s t}\right)\right]\right\}
\end{aligned}
$$

where $\mathbf{x}_{s t} \sim$ particular future under consideration, $\mathbf{x}_{s t, 0} \sim$ future involving no drilling intrusions but a mining event at the same time $t_{\min }$ as in $x_{s t}, f_{C}\left(x_{s t}\right) \sim$ cuttings and cavings release to accessible environment for $\mathbf{x}_{s t}$ calculated with CUTTINGS_S, $f_{B}\left(\mathbf{x}_{s t}\right) \sim$ two-phase flow results calculated for $\mathbf{x}_{s t}$ with BRAGFLO; in practice, $f_{B}\left(\mathbf{x}_{s l}\right)$ is a vector containing a large amount of information, $f_{S P}\left[\mathbf{x}_{s t}, f_{B}\left(\mathbf{x}_{s t}\right)\right] \sim$ spallings release to accessible environment for $\mathbf{x}_{s t}$ calculated with the spallings model contained in CUTTINGS_S; this calculation requires BRAGFLO results (i.e., $\left.f_{B}\left(\mathbf{x}_{s t}\right)\right)$ as input, $f_{D B R}\left\{\mathbf{x}_{s t}, f_{S P}\left[\mathbf{x}_{s t}, f_{B}\left(\mathbf{x}_{s t}\right)\right], f_{B}\left(\mathbf{x}_{s t}\right)\right\} \sim$ direct brine release to accessible environment for $\mathbf{x}_{s t}$ calculated with a modified version of BRAGFLO designated BRAGFLO_DBR; this calculation requires spallings results obtained from CUTTINGS_S (i.e., $f_{S P}\left[\mathbf{x}_{s t}, f_{B}\left(\mathbf{x}_{s t}\right)\right]$ ) and BRAGFLO results (i.e., $f_{B}\left(\mathbf{x}_{s t}\right)$ ) as input, $f_{M B}\left[\mathbf{x}_{s t}, f_{B}\left(\mathbf{x}_{s t}\right)\right] \sim$ release through anhydrite marker beds to accessible environment for $\mathbf{x}_{s t}$ calculated with NUTS; this calculation requires BRAGFLO results (i.e., $f_{B}\left(\mathbf{x}_{s t}\right)$ ) as input, $f_{D L}\left[\mathbf{x}_{s t}, f_{B}\left(\mathbf{x}_{s t}\right)\right] \sim$ release through Dewey Lake Red Beds to accessible environment for $\mathbf{x}_{s t}$ calculated with NUTS; this calculation requires BRAGFLO results (i.e., $\left.f_{B}\left(\mathbf{x}_{s t}\right)\right)$ as input, $f_{S}\left[\mathbf{x}_{s t}, f_{B}\left(\mathbf{x}_{s t}\right)\right]$ - release to land surface due to brine flow up a plugged borehole for $\mathbf{x}_{s t}$ calculated with NUTS or PANEL; this calculation requires BRAGFLO results (i.e., $\left.f_{B}\left(\mathbf{x}_{s i}\right)\right)$ as input, $f_{S-F}\left(\mathbf{x}_{s i, 0}\right) \sim$ flow field calculated for $\mathbf{x}_{s t, 0}$ with SECOFL2D, $f_{N-P}\left[\mathbf{x}_{s t}, f_{B}\left(\mathbf{x}_{s t}\right)\right] \sim$ release to Culebra for $\mathbf{x}_{s t}$ calculated with NUTS or PANEL as appropriate; this calculation requires BRAGFLO results (i.e., $f_{B}\left(\mathbf{x}_{s i}\right)$ ) as input, $f_{S-T}\left\{\mathbf{x}_{s t, 0}, f_{S-F}\left(\mathbf{x}_{s t, 0}\right), f_{N-P}\left[\mathbf{x}_{s t}, f_{B}\left(\mathbf{x}_{s t}\right)\right]\right\} \sim$ groundwater transport release through Culebra to accessible environment calculated with SECOTP2D; this calculation requires SECOFL2D results (i.e., $f_{S-F}\left(\mathbf{x}_{s t .0}\right)$ ) and NUTS 
or PANEL results (i.e., $f_{N-P}\left[\mathbf{x}_{s t}, f_{B}\left(\mathbf{x}_{s t}\right)\right]$ ) as input; $\mathbf{x}_{s t, 0}$ is used as an argument to $f_{S-T}$ because drilling intrusions are assumed to cause no perturbations to the flow field in the Culebra (Sect. 4, Ref. 1).

The function $f_{B}$ in Eq. (1) corresponds to the model used for two-phase flow in the 1996 WIPP PA, with the computational evaluation of this model being carried out by the BRAGFLO program (Fig. 2, Table 2, Ref. 1). This article describes the system of nonlinear partial differential equations that underlies the definition of $f_{B}$ and the context within which these equations are defined. The mathematical formulations of the other functions appearing in Eq. (1) (i.e., $f_{C}, f_{S P}, f_{D B R}, f_{M B}, f_{D L}, f_{S}, f_{S-T}, f_{S-F}, f_{N-P}$ ) are described in other articles. ${ }^{2-5}$ Further, additional articles present uncertainty and sensitivity analyses for two-phase flow results obtained under both disturbed and undisturbed condtions. ${ }^{6,7}$

This article is based on material contained in Sect. 4.2 of Ref. 8.

\section{Mathematical Description}

Two-phase flow in the vicinity of the repository is represented by the following system of two conservation equations, two constraint equations, and three equations of state:

Gas Conservation

$$
\begin{aligned}
& \nabla \cdot\left[\frac{\alpha \rho_{g} K_{g} k_{r g}}{\mu_{g}}\left(\nabla p_{g}+\rho_{g} g \nabla h\right)\right]+\alpha q_{w g}+\alpha q_{r g}=\alpha \frac{\partial\left(\phi \rho_{g} S_{g}\right)}{\partial t} \\
& \nabla \cdot\left[\frac{\alpha \rho_{b} K_{b} k_{r b}}{\mu_{b}}\left(\nabla p_{b}+\rho_{b} g \nabla h\right)\right]+\alpha q_{w b}+\alpha q_{r b}=\alpha \frac{\partial\left(\phi \rho_{b} S_{b}\right)}{\partial t}
\end{aligned}
$$

Brine Conservation

$$
S_{g}+S_{b}=1
$$

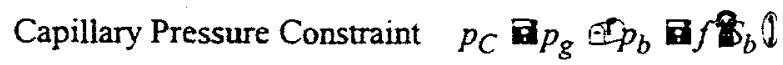

Gas Density $\rho_{g}$ determined by Redlich-Kwong-Soave equation of state (see Eqs. (31), (32))

Brine Density

$$
\rho_{b}=\rho_{0} \exp \left[\beta_{b}\left(p_{b}-p_{b 0}\right)\right]
$$

Formation Porosiry

$$
\phi=\phi_{0} \exp \left[\beta_{f}\left(p_{b}-p_{b 0}\right)\right]
$$

where $g=$ acceleration due to gravity $\left(\mathrm{m} / \mathrm{s}^{2}\right), h=$ vertical distance from a reference location $(\mathrm{m}) . \mathrm{K}_{l}=$ permeability tensor $\left(\mathrm{m}^{2}\right)$ for fluid $l\left(l=\mathrm{g} \sim \mathrm{gas}, l=b \sim\right.$ brine), $k_{r l}=$ relative permeability (dimensionless) to fluid, $p_{C}=$ capillary pressure $(\mathrm{Pa}), p_{l}=$ pressure of fluid $l(\mathrm{~Pa}), q_{r l}=$ rate of production (or consumption, if negative) of fluid $l$ due to chemical reaction $\left(\mathrm{kg} \mathrm{m}^{3} / \mathrm{s}\right), q_{\mathrm{w} /}=$ rate of injection (or removal, if negative) of fluid $l\left(\mathrm{~kg} / \mathrm{m}^{3} / \mathrm{s}\right), S_{l}=$ saruration of 
fluid $l$ (dimensionless), $t=$ time (s), $\alpha=$ geometry factor ( $\mathrm{m}$ in 1996 WIPP PA), $\rho_{l}=$ density of fluid $l\left(\mathrm{~kg} / \mathrm{m}^{3}\right), \mu_{l}=$ viscosity of fluid $l(\mathrm{~Pa} \mathrm{~s}), \phi=$ porosity (dimensionless), $\phi_{0}=$ reference (i.e., initial) porosity (dimensionless), $p_{b 0}=$ reference (i.e., initial) brine pressure ( $\mathrm{Pa}$ ), constant in Eq. (6) and spatially variable in Eq. (7), $\rho_{0}=$ reference (i.e., initial) brine density $\left(\mathrm{kg} / \mathrm{m}^{3}\right), \beta_{f}=$ pore compressibility $\left(\mathrm{Pa}^{-1}\right), \not \beta_{b}=$ brine compressibility $\left(\mathrm{Pa}^{-1}\right)$, and the capillary function $f$ is defined by the right hand sides of Eqs. (10), (19), and (22) as appropriate. The conservation equations are valid in one (i.e., $\nabla=[\partial / \partial x]$ ), two (i.e., $\nabla=[\partial / \partial x \partial / \partial y])$ and three (i.e., $\nabla=[\partial / \partial x \partial / \partial y \partial / \partial z])$ dimensions. In the 1996 WTPP PA, the preceding system of equations is used to model two-phase fluid flow within the twodimensional region shown in Fig. 1. Details of this system are now elaborated on.

The $\alpha$ term in Eqs. (2) and (3) is a dimension dependent geometry factor and is specified by

$\alpha=$ area normal to flow direction in one-dimensional flow (i.e., $\Delta y \Delta z$; units $=\mathrm{m}^{2}$ ),

$=$ thickness normal to flow plane in two-dimensional flow (i.e., $\Delta z$; units $=\mathrm{m}$ ),

$=1$ in three-dimensional flow (dimensionless).

The 1996 WIPP PA uses a two-dimensional geometry for computation of two-phase flow in the vicinity of the repository, and as a result, $\alpha$ is the thickness of the modeled region (i.e., $\Delta z$ ) normal to the flow plane (Fig. 2). Due to the use of the two-dimensional grid in Fig. 2, $\alpha$ is spatially dependent, with the values used for $\alpha$ defined in the column labeled "element depth" in Fig. 2. Specifically, $\alpha$ increases with distance away from the repository in both directions to incorporate the increasing pore volume through which fluid flow occurs.

The $h$ term in Eqs. (2) and (3) defines vertical distance from a reference point. In the 1996 WIPP PA, this reference point is taken to be the center of MB 139 at the location of the shaft (i.e., $\left(x_{\text {ref }}, y_{\text {ref }}\right)=(23664.9 \mathrm{~m}, 378.685$ $\mathrm{m})$, which is the center of cell 644 in Fig. 3). Specifically, $h$ is defined by

$$
h(x, y)=\left(x-x_{r e f}\right) \sin \theta+\left(y-y_{r e f}\right) \cos \theta,
$$

where $\theta$ is the inclination of the formation in which the point $(x, y)$ is located. In the 1996 WIPP PA, the Salado Fm is modeled as having an inclination of $1^{\circ}$ from north to south, and all other formations are modeled as being horizontal. Thus, $\theta=1^{\circ}$ for points within the Salado, and $\theta=0^{\circ}$ otherwise. Treating the Salado as an inclined formation and treating the Castile Fm, brine reservoir, Rustler Fm, and overlying units as horizontal creates discontinuities in the grid at the lower and upper boundaries of the Salado. However, this treatment does not create a computational problem as the Salado is isolated from vertical flow by the impermeable Unnamed Lower Member of the Rustler Fm at its upper boundary and by the impermeable Castile Fm at its lower boundary.

The primary model used in the 1996 WIPP PA for capillary pressure $p_{C}$ and relative permeability $k_{r l}$ is a modification of the Brooks-Corey model. ${ }^{9}$ Specifically, $p_{C}, k_{r b}$ and $k_{r g}$ are defined by

$$
p_{C}=p_{t}(k) / S_{e 2}^{1 / \lambda}
$$




$$
\begin{aligned}
& k_{r b}=S_{e 1}^{(2+3 \lambda) / \lambda} \\
& k_{r g}=\left(1-S_{e 2}\right)^{2}\left(1-S_{e 2}^{(2+\lambda) / \lambda}\right),
\end{aligned}
$$

where

$\lambda=$ pore distribution parameter (dimensionless)

$p_{l}(k)=$ capillary threshold pressure $(\mathrm{Pa})$ as a function of intrinsic permeability $k$ (Ref. 10$)$

$=a k^{\eta}$

$S_{e l}=$ effective brine saturation (dimensionless) without correction for residual gas saturation

$=\left(S_{b}-S_{b r}\right) /\left(1-S_{b r}\right)$

$S_{e 2}=$ effective brine saturation (dimensionless) with correction for residual gas saturation

$$
=\left(S_{b}-S_{b r}\right) /\left(1-S_{g r}-S_{b r}\right)
$$

The values used for $\lambda, a, \eta, S_{b r}, S_{g r}$ and $k$ are summarized in Tables 1 and 2 . The statement that the Brooks-Corey model is in use means that $p_{C}, k_{r b}$ and $k_{r g}$ are defined by Eqs. (10) - (12).

In the solution of Eqs. (2) and (3), $S_{b}$ and $S_{g}$ change as functions of location and time. Thus, $p_{C}, k_{r b}$ and $k_{r g}$ are functions of the form $p_{C}(x, y, t), k_{r b}(x, y, t)$ and $k_{r g}(x, y, t)$. In the computational implementation of the solution of the preceding equations, flow of phase $l$ out of a computational cell (Fig. 3) cannot occur when $S_{l}(x, y, t) \leq S_{l r}(x, y, t)$, where $S_{l r}$ denotes the residual saturation for phase $l$. The values used for $S_{l r}, l=b, g$, are summarized in Table 1.

Values for $\phi_{0}$ and $\beta_{f}$ (Eq. 7) are also given in Table 1. Initial porosity $\phi_{0}$ for the disturbed rock zone (DRZ) is a function of initial halite porosity $\phi_{0 H}$ (i.e., HALPOR in Table 1, Ref. 11) and is given by (Ref. 12; Chapt. 4, Ref. 13)

$$
\phi_{0}=\phi_{0 \mathrm{H}}+0.0029
$$

This representation is used because the DRZ and halite porosities are correlated, with the high, low and median porosity values for the DRZ being 0.0029 higher than the corresponding undisturbed halite values. Initial porosity $\phi_{0}$ for regions of pressurized brine in the Castile is a function of brine pocket volume and is given by

$$
\phi_{0}=V_{b r n} / V_{t o r},
$$


where $V_{b r n}$ is the volume of pressurized brine (i.e., $32,000,64,000,96,000,128,000$ or $160,000 \mathrm{~m}^{3}$ as defined by BPVOL in Table 1, Ref. 11) and $V_{\text {tot }}$ is the total volume associated with the region in Fig. 1 used to represent pressurized brine (i.e., region 30 , which has a total volume of $1.8389 \times 10^{7} \mathrm{~m}^{3}$ ).

The compressibilities $\beta_{f}$ in Eq. (7) and Table 1 are pore compressibilities. These compressibilities were treated as uncertain for Salado anhydrite, Salado halite, and regions of pressurized brine in the Castile (see ANHCOMP, HALCOMP, BPCOMP in Table 1, Ref. 11). However, the sampled values for these variables corresponded to bulk compressibilities rather than to the pore compressibilities actually used in the calculation. The conversion from bulk compressibility $\beta_{f B}$ to pore compressibility $\beta_{f}$ is approximated by

$$
\beta_{f}=\beta_{f B} / \phi_{0}
$$

in the 1996 WIPP PA, where $\phi_{0}$ is the initial porosity in the region under consideration.

The Brooks-Corey model is used for all materials with the following two exceptions (Table 3). First, whether to use the Brooks-Corey model or the van Genuchten-Parker model is treated as a subjective uncertainty for the anhydrite marker beds. Specifically, the variable $A N H B C V G P$ (see Table 1, Ref. 11) is used as a flag to determine whether the Brooks-Corey or van Genuchten-Parker model will be used in the representation of two-phase flow in the marker beds. Second, a linear model is used in the representation of two-phase flow in an open borehole (i.e., for the first $200 \mathrm{yr}$ after a drilling intrusion for plugging patterns $p_{2}$ and $p_{3}$ (see Sect. 6, Ref. 14)). Each of these alternatives to the Brooks-Corey model is now discussed.

In the van Genuchten-Parker model, $p_{C}, k_{r b}$ and $k_{r g}$ are defined by ${ }^{15}$

$$
\begin{aligned}
& p_{C}=p_{V G P}\left(S_{e 2}^{-1 / m}-1\right)^{1-m} \\
& k_{r b} \operatorname{as}_{e 1}^{1 / 2} \boldsymbol{k e t}_{e 1}^{1 / m j_{0}^{n_{0}^{2}}} \\
& k_{r g}=\left(1-S_{e 2}\right)^{1 / 2}\left(1-S_{e 2}^{1 / m}\right)^{2 m},
\end{aligned}
$$

where $m=\lambda(1+\lambda)$ and the capillary pressure parameter $p_{V G P}$ is determined by requiring that the capillary pressures defined in Eqs. (10) and (19) are equal at an effective brine saturation of $S_{c 2}=0.5$ (Ref. 10). The statement that the van Genuchten-Parker model is in use means that $p_{C}, k_{r b}$ and $k_{r g}$ are defined by Eqs. (19) - (21). The van Genuchten-Parker model is only used for the anhydrite marker beds in the Salado Formation (i.e., Regions 20, 21, 28 in Fig. 1) and uses the same values for $\lambda, S_{b r}$ and $S_{g r}$ as the Brooks-Corey model (Table 1). 
Capillary pressure $p_{C}$ for both the van Genuchten-Parker and Brooks-Corey models becomes unbounded as brine saturation $S_{b}$ approaches the residual brine saturation $S_{b r}$ To avoid unbounded values, $p_{C}$ is capped at $1 \times 10^{8} \mathrm{~Pa}$ in selected regions (Table 3 ).

In the linear model, $p_{C}, k_{r b}$ and $k_{r g}$ are defined by ${ }^{16}$

$$
p_{C}=0, k_{r b}=S_{e l}, k_{r g}=1-S_{e 1}
$$

As previously indicated, this model is only used for fluid flow in an open borehole.

The saturation and capillary pressure constraints (i.e., Eqs. 4, 5) permit a reduction of the number of equations to be solved from four (i.e., Eqs. 2 - 5) to two. In particular, the constraint equations are used to reformulate Eqs. (2) and (3) so that the unknown functions are gas saturation $S_{g}$ and brine pressure $p_{b}$. Specifically, the saturation constraint in Eq. (4) allows $S_{b}$ to be expressed as

$$
S_{b}=1-S_{g}
$$

and thus allows $S_{e 1}$ and $S_{e 2}$ in Eqs. (14) and (15) to be reformulated as

$$
\begin{aligned}
& S_{e 1}=\left(1-S_{g}-S_{b r}\right) /\left(1-S_{b r}\right) \\
& S_{e 2}=\left(1-S_{g}-S_{b r}\right) /\left(1-S_{g r}-S_{b r}\right)
\end{aligned}
$$

Further, the capillary pressure constraint in Eq. (5) allows $p_{g}$ to be expressed as

$$
\begin{array}{rlrl}
p_{g} & =p_{b}+p_{C} & \\
& =p_{b}+p_{t}(k) / S_{e 2}^{1 / 2} & & \text { for Brooks-Corey model, Eq. (10) } \\
& =p_{b}+p_{V G P}\left(S_{e 2}^{1 / m}-1\right)^{1-m} & & \text { for van Genuchten-Parker model, Eq. (19) } \\
& =p_{b} & & \text { for linear model, Eq. (22). }
\end{array}
$$

The equalities in Eqs. (24) - (28) allow the transformation of Eqs. (2) and (3) into two equations whose unknown functions are $S_{g}$ and $p_{b}$. which are the equations that are actually solved in BRAGFLO (Fig. 4). Once $S_{g}$ and $p_{b}$ are known, $S_{b}$ and $p_{g}$ can be obtained from Eq. (23) and Eqs. (26) - (28), respectively. 
All materials are assumed to be isotropic in the 1996 WIPP PA. ${ }^{17}$ Thus, the tensor $K_{l}$ in Eqs. (2) and (3) has the form

$$
K_{l}=\left[\begin{array}{cc}
k_{l} & 0 \\
0 & k_{l}
\end{array}\right]
$$

where $k_{l}$ is the permeability to fluid $l$ for the particular material under consideration. For brine (i.e., fluid $l=b$ ), the permeability $k_{b}$ is the same as the intrinsic permeability $k$ in Table 2 . For gas (i.e., fluid $l=g$ ), the permeability $k_{g}$ is obtained by modifying the intrinsic permeability $k$ to account for the Klinkenberg effect. ${ }^{18}$ Specifically,

$$
k_{g}=k\left(1+b k^{a} / p_{g}\right)
$$

where $a=a_{k l i n k}$ and $b=b_{k l i n k}$ are gas- and formation-dependent constants. For the 1996 WIPP PA, values of $a_{\text {klink }}=-0.3410$ and $b_{\text {klink }}=0.2710$ were determined from data obtained for MB 139 (Ref. 19), with these values used for all regions in Fig. 1. For fluid flow in the vicinity of the shaft, an averaging procedure was used to calculate $k$ that incorporates the permeability of the DRZ that surrounds portions of the shaft (see Sect. 3). Further, a pressuredependent modification of $k$ is used in the anhydrite marker beds in the presence of pressure-induced fracturing (see Sect. 5).

Gas density is computed using the Redlich-Kwong-Soave (RKS) equation of state, with the gas assumed to be pure hydrogen in the 1996 WIPP PA. For a pure gas, the RKS equation of state has the form (pp. 43-54, Ref. 20)

$$
p_{g}=\frac{R T}{V-b}-\frac{a \alpha}{V(V+b)}
$$

where $R=$ gas constant $=8.31451 \mathrm{~J} \mathrm{~mol}^{-1} \mathrm{~K}^{-1}, T=$ temperature $(\mathrm{K})=300.15 \mathrm{~K}\left(=30^{\circ} \mathrm{C}\right), V=$ molar volume $\left(\mathrm{m}^{3}\right.$ $\left.\mathrm{mol}^{-1}\right), a=0.42747 R^{2} T_{c}^{2} / P_{c}, b=0.08664 R T_{c} / P_{c}, \alpha=\left[1+\left(0.48508+1.55171 \omega-0.15613 \omega^{2}\right)\left(1-T_{r}^{0.5}\right)\right]^{2}$ and $1.202 \exp \left(-0.30288 T_{r}\right)$ for hydrogen, ${ }^{21} T_{c}=$ critical temperature $(\mathrm{K}), P_{c}=$ critical pressure $(\mathrm{Pa}), T_{r}=T / T_{c}=$ reduced temperature, and $\omega=$ acentric factor $=0$ for hydrogen. ${ }^{21}$ For hydrogen, pseudo-critical temperature and pressure values of $T_{c}=43.6 \mathrm{~K}$ and $P_{c}=2.047 \times 10^{6} \mathrm{~Pa}$ are used instead of the true values of these properties.22 Eq. (31) is solved for molar volume $V$. Then, the gas density $\rho_{g}$ is given by

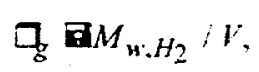

where $M_{w^{\prime}, H_{2}}$ is the molecular weight of hydrogen (i.e., $2.01588 \times 10^{-3} \mathrm{~kg} / \mathrm{mol}$; see p. B-26, Ref. 23).

Brine density $\rho_{b}$ is defined by Eq. (6), with $\rho_{0}=1230.0 \mathrm{~kg} / \mathrm{m}^{3}$ at a pressure of $p_{b 0}=1.0132 \times 10^{5} \mathrm{~Pa}$ and $\beta_{b}=2.5 \times 10^{-10} \mathrm{~Pa}^{-1}$ (Ref. 24). Porosity $\phi$ as defined by Eq. (7) is used with two exceptions: in the repository (see 
Sect. 4) and in the marker beds subsequent to fracturing (see Sect. 5). The values of $\phi_{0}$ and $\beta_{f}$ used in conjunction with Eq. (7) are listed in Table 1. The reference pressure $p_{b 0}$ in Eq. (7) is spatially variable and corresponds to the initial pressures $p_{b}(x, y,-5 \mathrm{yr})$ in Table 4. The gas and brine viscosities $\mu_{l}, l=g, b$, in Eqs. (2) and (3) were assumed to have values of $\mu_{g}=8.92 \times 10^{-6}$ Pa•s (Ref. 25) and $\mu_{b}=2.1 \times 10^{-3}$ Pa•s (Ref. 26).

The terms $q_{w g}, q_{r g}, q_{w b}$ and $q_{r b}$ in Eqs. (2) and (3) relate to well injection or removal (i.e., $q_{w g}, q_{w b}$ ) and reaction production or consumption (i.e., $q_{r g}, q_{r b}$ ) of gas and brine, with positive signs corresponding to injection or production and negative signs corresponding to removal or consumption. No injection or removal of gas or brine is assumed to take place within the region in Fig. 1. Thus, $q_{w g}$ and $q_{w b}$ are equal to zero in Eqs. (2) and (3). Further, no gas consumption occurs (see below), and gas production has the potential to occur (due to corrosion of steel or microbial degradation of cellulose, plastics or rubbers) only in the waste disposal panels of the repository (i.e., regions 23, 24 in Fig. 1). Thus,

$$
\begin{aligned}
q_{r g} & \geq 0 & & \text { in regions } 23,24 \text { of Fig. } 1 \\
& =0 & & \text { elsewhere. }
\end{aligned}
$$

Actually, some gas consumption does occur due to the reaction of $\mathrm{CO}_{2}$ with the $\mathrm{MgO}$ backfill in the waste panels. This gas consumption is accounted for by reducing the gas generation rate $q_{r g}$ and is discussed in more detail in Sect. 6.

Finally, no brine production occurs, and brine consumption has the potential to occur (due to the consumption of brine during the corrosion of steel) only in the waste disposal panels of the repository. Thus,

$$
\begin{aligned}
q_{r b} & \leq 0 & & \text { in regions 23, 24 of Fig. } 1 \\
& =0 & & \text { elsewhere. }
\end{aligned}
$$

More detail on the definition of $q_{r g}$ and $q_{r b}$ is provided in Sect. 6 .

\section{Shaft Treatment}

The WIPP excavation includes four distinct shafts connecting the repository region and the surface: the air intake, salt handing, waste, and exhaust shafts. In the 1996 WIPP PA, these four shafts are lumped into a single shaft located at the shaft position nearest the waste (region 2, Fig. 1). A rationale for this treatment is given in (Sect. 2.3, Vol. 5, Ref. 27).

The shaft seal design involves a complex composite of materials including earth, salt, clay, asphalt and concrete. The design is intended to control both short-term and long-term fluid flow through the Salado portion of the shaft. A conceptual representation of the shaft seal system used in 1996 WIPP PA is shown in Fig. 5. Four disturbed rock zones (DRZs) are located adjacent to the asphalt, clay and salt materials (regions 5, 7,8,9 in Fig. 1). Three DRZs 
have transient permeabilities, namely those surrounding the clay and crushed salt (i.e., regions 7, 8, 9 in Fig. 1). The DRZ adjacent to the asphalt column will heal over time but at a much slower rate than the DRZ adjacent to the Salado clay and salt components. To reduce the number of transient parameters, the DRZ adjacent to the asphalt column in the Salado (i.e., region 5 in Fig. 1) is assumed not to heal and its characteristics are treated as constant through time. Further, certain seal materials are assumed to have transient permeability values. Table 5 summarizes the seal and DRZ materials assumed to have transient permeabilities. In the conceptualization of the behavior of the shaft seals and their associated DRZs, the effective DRZ permeabilities are transient because the DRZ radii are transient, not because their intrinsic permeability changes with time. Table 6 summarizes the times at which permeabilities are changed for shaft seal and DRZ materials.

The effects of shaft and DRZ permeabilities are incorporated into the analysis for each shaft component through an effective permeability $k_{e}$ defined by

$$
k_{e}=\left(k_{s} \sum_{i=1}^{4} A_{s i}+k_{d} \sum_{i=1}^{4} A_{d i}\right) /\left(\sum_{i=1}^{4} A_{s i}\right)
$$

where $k_{s}=$ permeability $\left(\mathrm{m}^{2}\right)$ for shaft component under consideration, $A_{s i}=$ cross-sectional area $\left(\mathrm{m}^{2}\right)$ for shaft $i, k_{d}$ = permeability $\left(\mathbf{m}^{2}\right)$ for $\mathrm{DRZ}$ associated with shaft component under consideration, and $A_{d i}=$ cross-sectional area $\left(\mathrm{m}^{2}\right)$ for DRZ associated with shaft component under consideration for shaft $i$. A divisor of $\sum_{i=1}^{4} A_{s i}$ rather than $\sum_{i=1}^{4}\left(A_{s i}+A_{d i}\right)$ appears in Eq. (35) because the cross-sectional area used for the shaft is fixed at a value of $\sum_{i=1}^{4} A_{s i}$ (i.e., $\sim 95 \mathrm{~m}^{2}$ ) in the computational implementation of the analysis. The effective permeability $k_{e}$ plays the role of the intrinsic permeability $k$ in the definition of $K_{l}$ in Eq. (29) for sections of the shaft having a DRZ (i.e., regions 5, 7, 8, 9 in Fig. 1).

The permeability $k_{d}$ of each DRZ region is defined by ${ }^{28,29}$

$$
k_{d}=\frac{2}{r_{\text {out }}+r_{\text {in }}}\left[k_{\text {out }}\left(\frac{r_{\text {out }} \ln \left(\frac{k_{\text {out }}}{k_{\text {in }}}\right)-\Delta r}{\ln ^{2}\left(\frac{k_{\text {out }}}{k_{\text {in }}}\right)}\right)-k_{\text {in }}\left(\frac{r_{\text {in }} \ln \left(\frac{k_{\text {out }}}{k_{\text {in }}}\right)-\Delta r}{\ln ^{2}\left(\frac{k_{\text {out }}}{k_{\text {in }}}\right)}\right)\right],
$$

where $\Delta r=$ outer DRZ radius $\left(r_{\text {out }}\right)$ minus inner DRZ radius $\left(r_{\text {in }}\right)$, i.e., $r_{\text {out }}-r_{\text {in }}(\mathrm{m}), k_{\text {out }}=$ intact Salado formation permeability $\left(\mathrm{m}^{2}\right)$. and $k_{i n}=\mathrm{DRZ}$ skin permeability $\left(\mathrm{m}^{2}\right)$. The permeabilities $k_{o u t}$ and $k_{i n}$ are uncertain parameters in the 1996 WIPP PA (see HALPRM, SHPRMDRZ in Table 1, Ref. 11). The inner radii $r_{i n}$ in Eq. (36) and corresponding areas $A_{s i}$ in Eq. (35) of the four WIPP shafts are: 


\begin{tabular}{lccc} 
Shaft Name & $r_{i n}(\mathrm{~m})$ & $A_{s i}\left(\mathrm{~m}^{2}\right)$ \\
\cline { 1 - 1 } air intake & 3.09 & 30.0 \\
salt handling & 1.8 & 10.2 \\
waste & 3.5 & 38.5 \\
exhaust & 2.3 & 16.6
\end{tabular}

The normalized DRZ radii (i.e., the radial extent of the DRZ divided by the shaft radius $\left(r_{\text {out }} / r_{\text {in }}\right)$ ) are listed in Table 7. These normalized DRZ radii and the rate at which the DRZ heals are dependent on the adjacent shaft material, with the DRZ completely healed when $r_{\text {out }} / r_{i n}=1$. The DRZ area $A_{d i}$ in Eq. (35) is given by $\pi r_{\text {out }}^{2}-A_{s i}$, with $r_{\text {out }}$ obtained from $r_{\text {in }}$ and Table 7.

The two seal components that require transient $k_{s}$ values are the compacted salt and the concrete (Table 5). For the concrete component, the initial $k_{s}$ value is an uncertain parameter (see SHPRMCON in Table 1, Ref. 11), with $k_{s}$ reset to $1.0 \times 10^{-14} \mathrm{~m}^{2}$ at $400 \mathrm{yr}$. Salt permeabilities for the time intervals $[0,50 \mathrm{yr}],[50,100 \mathrm{yr}],[100,200 \mathrm{yr}]$ and $[200,10,000 \mathrm{yr}]$ are assumed to be uncertain but to have a rank correlation of 1 (see SHPRMHAL in Table 1 , Ref. 11).

\section{Creep Closure of Repository}

The porosity of the waste disposal regions (i.e., regions 23, 24 in Fig. 1) is assumed to change through time due to creep closure of the halite surrounding the excavations. The equations on which BRAGFLO is based do not incorporate this type of deformation. Therefore, the changes in repository porosity due to halite deformation are modeled in a separate analysis with the geomechanical program SANTOS, which implements a quasi-static, large deformation, finite element procedure. ${ }^{31,32}$ As described below, interpolation procedures are then used with the SANTOS results to define $\phi$ within the repository (see Eqs. (2) and (3)) as a function of time and pressure.

In the separate analysis, the SANTOS program is used to determine time-dependent pressures and porosities in the repository under different rates of gas generation (Figs. 6, 7). The designator $f$ in Figs. 6 and 7 corresponds to a scale factor on a base gas generation rate (i.e., $f=1$ ) of

$$
\begin{aligned}
r_{g}(t) & =2 \mathrm{~mol} / \text { drum } / \mathrm{yr} & & \text { for } 0 \leq t \leq 550 \mathrm{yr} \\
& =1 \mathrm{~mol} / \mathrm{drum} / \mathrm{yr} & & \text { for } 550<t \leq 1050 \mathrm{yr} \\
& =0 \mathrm{~mol} / \text { drum } / \mathrm{yr} & & \text { for } 1050<t \leq 10000 \mathrm{yr}
\end{aligned}
$$

Specifically, the gas generation rate $r_{g}(t, f)$ associated with the scale factor $f$ is given by

$$
r_{g}(t, f)=f r_{g}(t)
$$


for $0 \leq t \leq 10000 \mathrm{yr}$ and $f=0,0.025, \ldots, 2$ (see Figs. 6, 7). The pressure and porosity curves in Figs. 6 and 7 are calculated with the indicated values for $r_{g}(t, f)$ as described in Ref. 33 .

The porosities calculated by SANTOS are defined relative to a dynamically changing excavated volume. In contrast, the porosities used in BRAGFLO are defined relative to a fixed excavated volume. The pressures in Fig. 6 are pressures calculated by SANTOS. However, the porosities in Fig. 7 are porosities for use in BRAGFLO and are obtained from porosities calculated by SANTOS in a manner that results in the excavated volumes in SANTOS and BRAGFLO having equal pore volumes. Specifically, $\phi_{S} h_{S}=\phi_{B} h_{B}$, where $\phi_{S}$ and $\phi_{B}$ are the porosities associated with SANTOS and BRAGFLO and $h_{S}$ and $h_{B}$ are the heights $(m)$ of the excavated volume in SANTOS and BRAGFLO.

Brine pressures $p_{b}(t)$ obtained in the waste disposal regions are used in conjunction with the results in Figs. 6 and 7 to estimate porosity in regions 23 and 24 of Fig. 1 in the numerical solution of Eqs. (2) and (3). Given a value for $p_{b}(t)$, values $f_{1}$ and $f_{2}$ are determined such that

$$
p\left(t, f_{1}\right) \leq p_{b}(t)<p\left(t, f_{2}\right)
$$

where $p(t, f)$ denotes the pressure (Pa) at time $t$ obtained with gas generation rate $r_{g}(t, f)$ (see Fig. 6). An $f$ value associated with $p_{b}(t)$ is then given by

$$
\hat{f}=f_{1}+\left(\frac{p_{b}(t)-p\left(t, f_{1}\right)}{p\left(t, f_{2}\right)-p\left(t, f_{1}\right)}\right)\left(f_{2}-f_{1}\right),
$$

with $\hat{f}$ being estimated by linear interpolation on $f_{1}$ and $f_{2}$. With $\hat{f}$ determined, a corresponding porosity $\hat{\phi}$ for use with $p_{b}(t)$ is obtained from the porosity results in Fig. 7. Specifically,

$$
\hat{\phi}=\phi\left(t, f_{1}\right) \div\left(\frac{\hat{f}-f_{1}}{f_{2}-f_{1}}\right)\left(\phi\left(t, f_{2}\right)-\phi\left(t, f_{1}\right)\right)
$$

where $\phi(t, f)$ denotes the porosity at time $t$ obtained with gas generation rate $r_{g}(t, f)$ (see Fig. 7 ).

\section{Interbed Fracturing}

Fracturing within the anhydrite marker beds (i.e., regions 20, 21, 28 in Fig. 1) is assumed to occur at pressures slightly below lithostatic pressure and is implemented through a pressure-dependent compressibility $\beta_{f}\left(p_{b}\right)$. Specifically, the following assumptions are made: ${ }^{34}$ (1) Fracturing of the marker beds begins at a brine pressure of

$$
p_{b i}=p_{b 0}+\not p_{i}
$$


where $p_{b i}$ and $p_{b 0}$ are spatially dependent (i.e., $p_{b 0}=p_{b}(x, y,-5)$ in Table 4) and $\Delta p_{i}=2 \times 10^{5} \mathrm{~Pa}$. (2) Fracturing ceases at a pressure of

$$
p_{b a}=p_{b i}+\Delta p_{a}
$$

and a fully fractured porosity of

$$
\phi\left(p_{b a}\right)=\phi_{a}=\phi_{0}+\Delta \phi_{a}
$$

where $\Delta p_{a}=3.8 \times 10^{6} \mathrm{~Pa}$, $\phi_{0}$ is spatially dependent (i.e., $\phi_{0}=\phi_{0}(x, y,-5)$ in Table 4), and $\Delta \phi_{a}=0.04,0.24$ and 0.04 for MB 138, MB A\&B and MB 139, respectively (i.e., $\phi_{a}=0.05,0.25$. 0.05 for MB 138, MB A\&B, MB 139). (3) Compressibility $\beta_{f}$ is a linear function

$$
\beta_{f}\left(p_{b}\right)=\beta_{f}+\left(\frac{p_{b}-p_{b i}}{p_{b a}-p_{b i}}\right)\left(\beta_{f a}-\beta_{f}\right)
$$

of brine pressure for $p_{b i} \leq p_{b} \leq p_{b a}$, with $\beta_{f a}$ defined so that the solution $\phi$ of

$$
d \phi / d p_{b}=\beta_{f}\left(p_{b}\right) \phi, \phi\left(p_{b i}\right)=\phi_{0} \exp \left[\beta_{f}\left(p_{b i}-p_{b 0}\right)\right]
$$

satisfies $\phi\left(p_{b a}\right)=\phi_{a}$; specifically, $\beta_{f a}$ is given by

$$
\beta_{f a}=\beta_{f}\left[1-\frac{2\left(p_{b a}-p_{b 0}\right)}{p_{b a}-p_{b i}}\right]+\left[\frac{2}{p_{b a}-p_{b i}}\right] \ln \left(\frac{\phi_{a}}{\phi_{0}}\right) .
$$

(4) The permeability $k_{f}\left(p_{b}\right)$ of fractured material at brine pressure $p_{b}$ is related to the permeability $k_{i}$ of unfractured material at brine pressure $p_{b i}$ by

$$
k_{f}\left(p_{b}\right)=\left[\phi\left(p_{b}\right) / \phi\left(p_{b i}\right)\right]^{n} k
$$

where $k$ is the permeability of unfractured material (i.e., at $p_{b i}$ ) and $n$ is defined so that $k_{f}\left(p_{b a}\right)=1 \times 10^{-9} \mathrm{~m}^{2}$ (i.e., $n$ is a function of $k$, which is an uncertain input to the analysis; see ANHPRM in Table 1, Ref. 11). When fracturing occurs, $k_{f}\left(p_{b}\right)$ is used instead of $k$ in the definition of the permeability tensor $K_{l}$ in Eq. (29) for the fractured areas of the anhydrite marker beds.

\section{Gas Generation}

Gas production is assumed to result from anoxic corrosion of steel and microbial degradation of cellulosics, plastics and rubbers. Thus, the gas generation rate $q_{r g}$ in Eq. (2) is of the form 


$$
q_{r g}=q_{r g c}+q_{r g m}
$$

where $q_{r g c}$ is the rate of gas production due to anoxic corrosion of steel $\left(\mathrm{kg} / \mathrm{m}^{3} / \mathrm{s}\right)$ and $q_{r g m}$ is the rate of gas production due to microbial degradation of cellulosics, plastics and rubbers $\left(\mathrm{kg} / \mathrm{m}^{3} / \mathrm{s}\right)$. Gas generation takes place only within the waste disposal region (i.e., regions 23,24 of Fig. 1) and all the generated gas is assumed to have the same properties as $\mathrm{H}_{2}$. Furthermore, $q_{r b}$ in Eq. (3) is used to describe the consumption of brine during the corrosion process.

The rates $q_{r g c} q_{r}$ and $q_{r g m}$ are defined by

$$
\begin{aligned}
& q_{r g c}=\left(R_{c i} S_{b, e f f}+R_{c h} S_{g}^{*}\right) D_{s} \rho_{F e} X_{c}\left(\mathrm{H}_{2} \mid \mathrm{Fe}\right) M_{\mathrm{H}_{2}} \\
& q_{r b}=-\left(q_{r g c} / M_{\mathrm{H}_{2}}\right) X_{c}\left(\mathrm{H}_{2} \mathrm{O} \mathrm{H}_{2}\right) M_{\mathrm{H}_{2} \mathrm{O}} /\left(1-\omega_{s}\right) \\
& q_{r g m}=\left(R_{m i} S_{b . e f f}+R_{m h} S_{g}^{*}\right) D_{c} y\left(\mathrm{H}_{2} \mid \mathrm{C}\right) M_{\mathrm{H}_{2}}
\end{aligned}
$$

where $D_{s}=$ surface area concentration of steel in the repository $\left(\left(\mathrm{m}^{2}\right.\right.$ surface area steel $) /\left(\mathrm{m}^{3}\right.$ disposal volume $\left.)\right), D_{c}=$ mass concentration of cellulosics in the repository ( $\mathrm{kg}$ biodegradable material) $/\left(\mathrm{m}^{3}\right.$ of disposal volume),$M_{\mathrm{H}_{2}}=$ molecular weight of $\mathrm{H}_{2}\left(\left(\mathrm{~kg} \mathrm{H}_{2}\right) /\left(\mathrm{mol} \mathrm{H}_{2}\right)\right), \quad M_{\mathrm{H}_{2} \mathrm{O}}=$ molecular weight of $\mathrm{H}_{2} \mathrm{O}\left(\left(\mathrm{kg} \mathrm{H}_{2} \mathrm{O}\right) /\left(\mathrm{mol} \mathrm{H}_{2} \mathrm{O}\right)\right), R_{c i}=$ corrosion rate under inundated conditions $(\mathrm{m} / \mathrm{s}), R_{c h}=$ corrosion rate under humid conditions $(\mathrm{m} / \mathrm{s}), R_{m i}=$ rate of cellulose biodegradation under inundated conditions ( $\mathrm{mol} \mathrm{CH}_{2} \mathrm{O} / \mathrm{kg} \mathrm{CH}_{2} \mathrm{O} / \mathrm{s}$ ), $R_{m h}=$ rate of cellulose bioudegradation under humid conditions ( $\mathrm{mol} \mathrm{C \textrm {C } _ { 2 }} \mathrm{O} / \mathrm{kg} \mathrm{CH}_{2} \mathrm{O} / \mathrm{s}$ ), $\quad S_{b, e f f}=$ effective brine saturation due to capillary action in the waste materials (see Eq. (72) in Sect. 7), $S_{g}^{*}=1-S_{b, \text { eff }}$ if $S_{b, \text { eff }}>0$ and 0 if $S_{b, e f f}=0, X_{c}\left(\mathrm{H}_{2} \mid \mathrm{Fe}\right)=$ stoichiometric coefficient for gas generation due to corrosion of steel, i.e., moles of $\mathrm{H}_{2}$ produced by the corrosion of 1 mole of $\mathrm{Fe}$ $\left(\left(\mathrm{mol} \mathrm{H}_{2}\right) /(\mathrm{mol} \mathrm{Fe})\right), X_{c}\left(\mathrm{H}_{2} \mathrm{O} \mathrm{H}_{2}\right)=$ stoichiometric coefficient for brine consumption due to corrosion of steel, i.e., moles of $\mathrm{H}_{2} \mathrm{O}$ consumed per mole of $\mathrm{H}_{2}$ generated by corrosion $\left(\left(\operatorname{mol~} \mathrm{H}_{2} \mathrm{O} /\left(\mathrm{mol} \mathrm{H} \mathrm{H}_{2}\right)\right), \quad,\left(\mathrm{H}_{2} \mid \mathrm{C}\right)=\right.$ average stoichiometric factor for microbial degradation of cellulose, i.e., the moles of $\mathrm{H}_{2}$ generated per mole of carbon consumed by microbial action $\left(\left(\mathrm{mol} \mathrm{H}_{2}\right) /\left(\mathrm{mol} \mathrm{CH}_{2} \mathrm{O}\right)\right), \rho_{F e}=\operatorname{molar}$ density of steel $\left(\mathrm{mol} / \mathrm{m}^{3}\right)$, and $\omega_{s}=$ weight fraction of dissolved solids in brine ( $\mathrm{kg}$ dissolved solids $/ \mathrm{kg}$ brine).

The products $R_{c i} D_{s} \rho_{F e} X_{c} R_{c h} D_{s} \rho_{F e} X_{c}, R_{m i} D_{c} y$ and $R_{m h} D_{c} y$ in Eqs. (50) and (52) define constant rates of gas generation ( $\mathrm{mol} / \mathrm{m}^{3} / \mathrm{s}$ ) that continue until the associated substrate (i.e. steel or cellulose) is exhausted (i.e., zero order kinetics). The terms $S_{b . e f f}$ and $S_{g}^{*}$ in Eqs. (50) and (52), which are functions of location and time, correct for the amount of substrate that is exposed to inundated and humid conditions, respectively. All the corrosion and microbial action is assumed to cease when no brine is present, which is the reason that 0 replaces $S_{g}=1$ in the definition of $S_{g}^{*}$. In the 1996 WIPP PA. $R_{c h}=0$ and $R_{c i}, R_{m h}$ and $R_{m i}$ are defined by uncertain variables (see WGRCOR, WGRMICH. WGRMICI in Table 1. Ref. 11). Further, $M_{H_{2}}=2.02 \times 10^{-3} \mathrm{~kg} / \mathrm{mol}$ (pp. 17-18, Ref. 35). 
$M_{\mathrm{H}_{2} \mathrm{O}}=1.80 \times 10^{-2} \mathrm{~kg} / \mathrm{mol}$ (pp. 17-18, Ref. 35), $\rho_{F e}=1.41 \times 10^{5} \mathrm{~mol} / \mathrm{m}^{3}$ (Ref. 36), and $D_{s}, D_{c}, X_{c}\left(\mathrm{H}_{2} \mathrm{O} \mid \mathrm{H}_{2}\right)$, $X_{c}\left(\mathrm{H}_{2} \mid \mathrm{Fe}\right)$ and $y\left(\mathrm{H}_{2} \mid \mathrm{C}\right)$ are discussed below.

The concentration $D_{s}$ in Eq. (50) is defined by

$$
D_{s}=A_{d} n_{d} / V_{R}
$$

where $A_{d}=$ surface area of steel associated with a waste disposal drum $\left(\mathrm{m}^{2} / \mathrm{drum}\right), V_{R}=$ initial volume of the repository $\left(\mathrm{m}^{3}\right)$, and $n_{d}=$ number of waste drums required to hold all the waste emplaced in the repository (drums). In the 1996 WIPP PA, $A_{d}=6 \mathrm{~m}^{2} / \mathrm{drum}$ (Vol. 3, Ref. 37), $V_{R}=436,023 \mathrm{~m}^{3}$ (Ref. 37), and $n_{d}=814,044$ drums (Ref. 38; pp. 51-53, Ref. 39; Ref. 40).

The biodegradable materials to be disposed at the WIPP consist of cellulosics, rubbers, and both waste plastics and container plastics. Cellulosics have been demonstrated experimentally to be the most biodegradable among these materials. ${ }^{41}$ The occurrence of significant microbial gas generation in the repository will depend on: (1) whether microbes capable of consuming the emplaced organic materials will be present and active; (2) whether sufficient electron acceptors will be present and available; and (3) whether enough nutrients will be present and available. Given the uncertainties in these factors, a probability of 0.5 is assigned to the occurrence of microbial gas generation (see WMICDFLG in Table 1, Ref. 11). Furthermore, two factors may increase the biodegradability of plastics and rubbers: long time scale and cometabolism. Over a time scale of $10,000 \mathrm{yr}$, the chemical properties of plastics and rubbers may change, increasing their biodegradability. Cometabolism means that microbes may degrade organic compounds, but do not use them as a source of energy, which is derived from other substrates. Both of these factors are highly uncertain and therefore a probability of 0.5 is assigned to biodegradation of plastics and rubbers conditional on the occurrence of biodegradation of cellulose (see WMICDFLG in Table 1, Ref. 11). In cases where biodegradation of rubbers and plastics occurs, rubbers and plastics are converted to an equivalent quantity of cellulosics based on their carbon equivalence. ${ }^{42}$ This produces the density calculation

$$
D_{c}= \begin{cases}m_{c e l} / V_{R} & \text { for biodegradation of cellulosics only } \\ \left(m_{c c l}+m_{r}+1.7 m_{p}\right) / V_{R} & \text { for biodegradation of cellulosics, rubber, plastics, }\end{cases}
$$

where $m_{c e l}$ is mass of cellulosics $(\mathrm{kg}), m_{r}$ is the mass of rubbers $(\mathrm{kg})$, and $m_{p}$ is the mass of plastics $(\mathrm{kg})$. The factor of 1.7 converts all plastics to an equivalent quantity of cellulosics based on carbon equivalence. In the 1996 WIPP $\mathrm{PA}, m_{c e l}=9.25 \times 10^{6} \mathrm{~kg}, m_{r}=1.71 \times 10^{6} \mathrm{~kg}$ and $m_{p}=1.03 \times 10^{7} \mathrm{~kg}$ (Ref. 43 ).

The most plausible corrosion reactions after closure of the WIPP are believed to be ${ }^{42}$

$$
\mathrm{Fe}+2 \mathrm{H}_{2} \mathrm{O}=\mathrm{Fe}(\mathrm{OH})_{2}+\mathrm{H}_{2}
$$

and 
$3 \mathrm{Fe}+4 \mathrm{H}_{2} \mathrm{O}=\mathrm{Fe}_{3} \mathrm{O}_{4}+4 \mathrm{H}_{2}$

When linearly weighted by the factors $x$ and $1-x(0 \leq x \leq 1)$, the two preceding reactions become

$$
\mathrm{Fe}+\left(\frac{4+2 x}{3}\right) \mathrm{H}_{2} \mathrm{O}=\left(\frac{4-x}{3}\right) \mathrm{H}_{2}+x \mathrm{Fe}(\mathrm{OH})_{2}+\left(\frac{1-x}{3}\right) \mathrm{Fe}_{3} \mathrm{O}_{4}
$$

where $x$ and $1-x$ are the fractions of iron consumed in the reactions in Eqs. (55) and (56), respectively.

Although magnetite $\left(\mathrm{Fe}_{3} \mathrm{O}_{4}\right)$ has been observed to form on iron as a corrosion product in low-Mg anoxic brines at elevated temperatures ${ }^{44}$ and in oxic brine, ${ }^{45}$ there is no evidence that it will form at WIPP repository temperatures. If $\mathrm{Fe}_{3} \mathrm{O}_{4}$ were to form, $\mathrm{H}_{2}$ would be produced (on a molar basis) in excess of the amount of $\mathrm{Fe}$ consumed. However, anoxic corrosion experiments ${ }^{36}$ did not indicate the production of $\mathrm{H}_{2}$ in excess of the amount of Fe consumed. Therefore, the stoichiometric factor $x$ in Eq. (57) is set to 1.0 (i.e., $x=1$ ) in the 1996 WIPP PA, which implies that Eq. (55) represents corrosion. Thus, the stoichiometric factor for corrosion is

$$
X_{c}\left(\mathrm{H}_{2} \mid \mathrm{Fe}\right)=(4-x) / 3=1 \mathrm{~mol} / \mathrm{mol} \text {, }
$$

which implies that one mole of $\mathrm{H}_{2}$ is produced for each mole of iron consumed, and the stoichiometric factor for brine consumption is

$$
X_{c}\left(\mathrm{H}_{2} \mathrm{O} / \mathrm{H}_{2}\right)=(4+2 x) / 3=2 \mathrm{~mol} / \mathrm{mol}
$$

which implies that two moles of $\mathrm{H}_{2} \mathrm{O}$ are consumed for each mole of $\mathrm{H}_{2}$ produced.

The divisor $1-\omega_{s}$ in Eq. (51) converts from water $\left(\mathrm{H}_{2} \mathrm{O}\right)$ consumed in the corrosion process to an equivalent amount of brine, with $\omega_{s}=0.324$ in the 1996 WIPP PA. No attempt is made to incorporate the potential effects of the precipitated solids on porosity or permeability in the waste panels.

The most plausible biodegradation reactions after closure of the WIPP are believed to be ${ }^{42}$

$$
\begin{aligned}
& \text { reaction } 1 \text { (denitrification): } \mathrm{C}_{6} \mathrm{H}_{10} \mathrm{O}_{5}+4.8 \mathrm{H}^{+}+4.8 \mathrm{NO}_{3}^{-}=7.4 \mathrm{H}_{2} \mathrm{O}+6 \mathrm{CO}_{2}+2.4 \mathrm{~N}_{2} \\
& \text { reaction } 2 \text { (sulfate reduction): } \mathrm{C}_{6} \mathrm{H}_{10} \mathrm{O}_{5}+6 \mathrm{H}^{+}+3 \mathrm{SO}_{4}^{2-}=5 \mathrm{H}_{2} \mathrm{O}+6 \mathrm{CO}_{2}+3 \mathrm{H}_{2} \mathrm{~S} \\
& \text { reaction } 3 \text { (methanogensis): } \mathrm{C}_{6} \mathrm{H}_{10} \mathrm{O}_{5}=\mathrm{CH}_{4}+3 \mathrm{CO}_{2} .
\end{aligned}
$$

The accumulation of $\mathrm{CO}_{2}$ produced by the above reactions will decrease $\mathrm{pH}$ and thus increase actinide solubility in the repository. ${ }^{46}$ To improve WIPP performance, a sufficient amount of $\mathrm{MgO}$ will be added to the repository as 
backfill to remove $\mathrm{CO}_{2}$ and buffer $\mathrm{pH}^{47}$ The consumption of $\mathrm{CO}_{2}$ by $\mathrm{MgO}$ in the repository takes place by the reaction

$$
\mathrm{MgO}+\mathrm{CO}_{2}=\mathrm{MgCO}_{3}
$$

Given the current waste inventory estimates, the minimum amount of $\mathrm{MgO}$ sufficient to remove all $\mathrm{CO}_{2}$ is estimated to be $4 \times 10^{8} \mathrm{~mol}$, which is about $4 \%$ of total transuranic waste volume. ${ }^{43}$ The amount recommended for use in the WIPP is $2 \times 10^{9} \mathrm{~mol}$ (App. Source Term, Ref. 48). The effect of $\mathrm{CO}_{2}$ consumption by $\mathrm{MgO}$ on fluid flow is not explicitly represented by a negative gas generation rate $q_{r g}$. Rather, the effect of $\mathrm{CO}_{2}$ consumption is accounted for by modifying the stoichiometry of Eqs. (60) - (62).

The average stoichiometry of Eqs. (60) - (62) is

$$
\mathrm{C}_{6} \mathrm{H}_{10} \mathrm{O}_{5}+\text { unknown }=6 y(\mathrm{~mol}) \text { gas }+ \text { unknowns. }
$$

The average stoichiometric factor $y$ in Eq. (64) depends on the extent of the individual biodegradation pathways in Eqs. (60) - (62) and the consumption of $\mathrm{CO}_{2}$ by $\mathrm{MgO}$. This factor is based on estimates of the transuranic waste to be emplaced in the WIPP (Refs. 43,49 ) and is derived as follows. ${ }^{42,} 46$

Estimates of the maximum quantities $M_{c e l}$ and $M_{F e}$ (mol) of cellulosics (i.e., $\mathrm{CH}_{2} \mathrm{O}$ ) and steels that can be potentially consumed in $10,000 \mathrm{yr}$ are given by

$$
\begin{aligned}
& M_{c e l}=\min \left\{\frac{6000 m_{c e l}}{162}, 3.2 \times 10^{11} R_{m} m_{c e l}\right\} \\
& M_{F e}=\min \left\{\frac{1000 m_{F e}}{56}, 4.4 \times 10^{16} R_{c i} A_{d} n_{d}\right\},
\end{aligned}
$$

where

$$
R_{m}=\max \left\{R_{m, i}, R_{m . h}\right\}
$$

and $m_{c e l}$ and $m_{F e}$ are the masses (kg) of cellulosics (see Eq. 54) and steels initially present in the repository $\left(m_{F e}=7: 13 \times 10^{7} \mathrm{~kg}\right.$; see Ref. 43). The terms $6000 m_{c e l} / 162$ and $1000 m_{F e} / 56$ in Eqs. (65) and (66) equal the inventories in moles of cellulosics and steel, respectively. The terms $3.2 \times 10^{11} R_{m} m_{c e l}$ and $4.4 \times 10^{16} R_{c i} A_{d} n_{d}$ equal the maximum amounts of cellulosics and steel that could be consumed over 10,000 yr. In Eq. (65), $3.2 \times 10^{11} \mathrm{Ps}$ $\left(3.15569 \times 10^{7} \mathrm{~s} / \mathrm{yr}\right)\left(10^{4} \mathrm{yr}\right)$. In Eq. (66), $A_{d} n_{d}$ is the total surface area of all drums $\left(\mathrm{m}^{2}\right)$ and the factor $4.4 \times 10^{16}$ $\curvearrowright\left(3.15569 \times 10^{7} \mathrm{~s} / \mathrm{yr}\right)\left(10^{4} \mathrm{yr}\right)\left(1.41 \times 10^{5} \mathrm{~mol} / \mathrm{m}^{3}\right)$, where $\rho_{F e}=1.41 \times 10^{5} \mathrm{~mol} / \mathrm{m}^{3}$ (see Eq. 50) (Ref. 36) converts the corrosion rate from $\mathrm{m} / \mathrm{s}$ to $\mathrm{mol} / \mathrm{m}^{2} / \mathrm{s}$. 
A range of possible values for the average stoichiometric factor $y$ in Eq. (64) can be obtained by considering individual bjodegradation pathways involving $M_{c e l}$ and accounting for the removal of $\mathrm{CO}_{2}$ according to Eq. (63). Two extreme cases corresponding to the maximum and minimum values of $y$ exist: (1) there is no reaction of microbially produced $\mathrm{H}_{2} \mathrm{~S}$ with ferrous metals and metal corrosion products, and (2) there is a complete reaction of microbially produced $\mathrm{H}_{2} \mathrm{~S}$ with ferrous metals and metal corrosion products. If no $\mathrm{H}_{2} \mathrm{~S}$ is consumed by reactions with iron and iron corrosion products, the maximum quantity of microbial gas will be retained in the repository and therefore the maximum value for $y$ results. Thus, the maximum value of $y$ can be estimated by averaging the gas yields for all reaction pathways to produce

$$
y_{\max }=\frac{\frac{2.4 M_{N O_{3}}}{4.8}+\frac{3 M_{S O_{4}}}{3}+0.5\left(M_{c e l}-\frac{6 M_{N O_{3}}}{4.8}-\frac{6 M_{S O_{4}}}{3}\right)}{M_{c e l}},
$$

where $\mathrm{M}_{\mathrm{NO}_{3}}$ and $\mathrm{MSO}_{4}$ are the quantities of $\mathrm{NO}_{3}^{-}$and $\mathrm{SO}_{4}^{2-}$ (in moles) initially present in the repository. Specifically, $M_{\mathrm{NO}_{3}}=2.61 \times 10^{7} \mathrm{~mol}$ and $M_{\mathrm{SO}_{4}}=6.59 \times 10^{6} \mathrm{~mol}$ (Ref. 49 ).

If $\mathrm{H}_{2} \mathrm{~S}$ reacts with iron and iron corrosion products, a significant quantity or perhaps all of the microbially produced $\mathrm{H}_{2} \mathrm{~S}$ would be consumed to produce $\mathrm{FeS}$, which would result in the minimum value of $y$. Specifically,

$$
y_{\text {min }}=\frac{\frac{2.4 M_{N O_{3}}}{4.8}+\frac{3 M_{S O_{4}}}{3}+0.5\left(M_{c e l}-\frac{6 M_{N O_{3}}}{4.8}-\frac{6 M_{S O_{4}}}{3}\right)-G}{M_{c e l}}=y_{\max }-\frac{G}{M_{c e l}},
$$

where

$$
G=\min \left\{\frac{3 M_{S O_{4}}}{3}, M_{F e}\right\}
$$

The stoichiometric factor $y$ value is believed to be located within the interval $\left[y_{\text {min }}, y_{\text {max }}\right]$. That is,

$$
y=y_{\text {min }}+\beta\left(y_{\text {max }}-y_{\text {min }}\right), 0 \leq \beta \leq 1 \text {. }
$$

The variable $\beta$ in the preceding equation is treated as an uncertain quantity in the 1996 WIPP PA (see WFBETCEL in Table 1, Ref. 11).

\section{Capillary Action in the Waste}

Capillary action (wicking) refers to the ability of a material to carry a fluid by capillary forces above the level it would normally seek in response to gravity. In the current analysis, this phenomena is accounted for by defining an effective saturation given by 


$$
\begin{aligned}
S_{b . e f f} & =S_{b}-S_{\text {wick }} & & \text { if } 0<S_{b}<1-S_{\text {wick }} \\
& =0 & & \text { if } S_{b}=0 \\
& =1 & & \text { if } S_{b}>1-S_{\text {wick }}
\end{aligned}
$$

where $S_{b . \text { eff }}=$ effective brine saturation, $S_{b}=$ brine saturation, and $S_{\text {wick }}=$ wicking saturation. The effective saturation is used on a grid block basis (Fig. 1) within all waste regions. The wicking saturation, $S_{\text {wick }}$, is treated as an uncertain variable (see WASTWICK in Table 1, Ref. 11). The effective brine saturation $S_{b, e f f}$ is only used in the calculation of the corrosion of steel (Eq. (50)) and the microbial degradation of cellulose (Eq. (52)) and does not directly affect the two phase flow calculations indicated in Eqs. (2) - (7).

\section{Borehole Model}

The major disnuptive event in the 1996 WIPP PA is the penetration of the repository by a drilling intrusion. Such an intrusion is modeled by modifying the permeability of region 1 in Fig. 1 (Table 8). Further, the drilling intrusion is assumed to produce a borehole with a diameter of $12.25 \mathrm{in} .(0.31 \mathrm{~m})$ (Refs. 51, 52); borehole fill is assumed to be incompressible; capillary effects are ignored; residual gas and brine saturations are set to zero, and porosity is set to 0.32 (see materials $47,48,49,50$ in Table 1). When a borehole that penetrates pressurized brine in the Castile Fm is under consideration (i.e., an $\mathrm{El}$ intrusion), the permeability modifications indicated in Table 8 extend from the land surface (i.e., grid cell 937 in Fig. 3) to the base of the pressurized brine (i.e., grid cell 1010 in Fig. 3). When a borehole that does not penetrate pressurized brine in the Castile $\mathrm{Fm}$ is under consideration (i.e., an E2 intrusion), the permeability modifications indicated in Table 8 stop at the bottom of the lower DRZ (i.e., grid cell 439 in Fig. 3).

\section{Numerical Solution}

Determination of gas and brine flow in the vicinity of the repository requires the numerical solution of the two nonlinear partial differential equations in Fig. 4 on the computational domain in Fig. 1 together with evaluation of appropriate auxiliary conditions (i.e., Eqs. $4-7,26-28$ ). The actual unknown functions in this solution are $p_{b}$ and $S_{g}$, although the constraint conditions also give rise to values for $p_{g}$ and $S_{b}$. As two dimensions in space and one dimension in time are in use, $p_{b}, p_{g}, S_{b}$ and $S_{g}$ are functions of the form $p_{b}(x, y, t), p_{g}(x, y, t), S_{b}(x, y, t)$ and $S_{g}(x, y$, i).

The solution of the equations in Fig. 4 requires both initial value and boundary value conditions for $p_{b}$ and $S_{g}$. The initial value conditions for $p_{b}$ and $S_{g}$ are given in Table 4. As indicated there, the calculation starts at time $t=-5 \mathrm{yr}$, with a possible resetting of values at $\mathrm{t}=0 \mathrm{yr}$, which corresponds to final waste emplacement and sealing of the repository. The boundary conditions are such that no brine or gas moves across the exterior grid boundary (Table 9). This Neumann-type boundary condition is maintained for all time. Further, BRAGFLO allows the user to specify pressure and/or saruration at any grid block. This feature is used to specify Dirichlet-type conditions at the surface grid blocks $i=1.2 \ldots .33,=31$, Fig. 1 ) and at the far field locations in the Culebra and Magenta Formations 
$(i=1,33, j=24$ and $i=1,33, j=26$ in regions 15 and 17 , Fig. 1). These auxiliary conditions are summarized in Table 10.

A fully implicit finite difference procedure is used to solve the two partial differential equations in Fig. 4. The associated discretization of the gas mass balance equation is given by
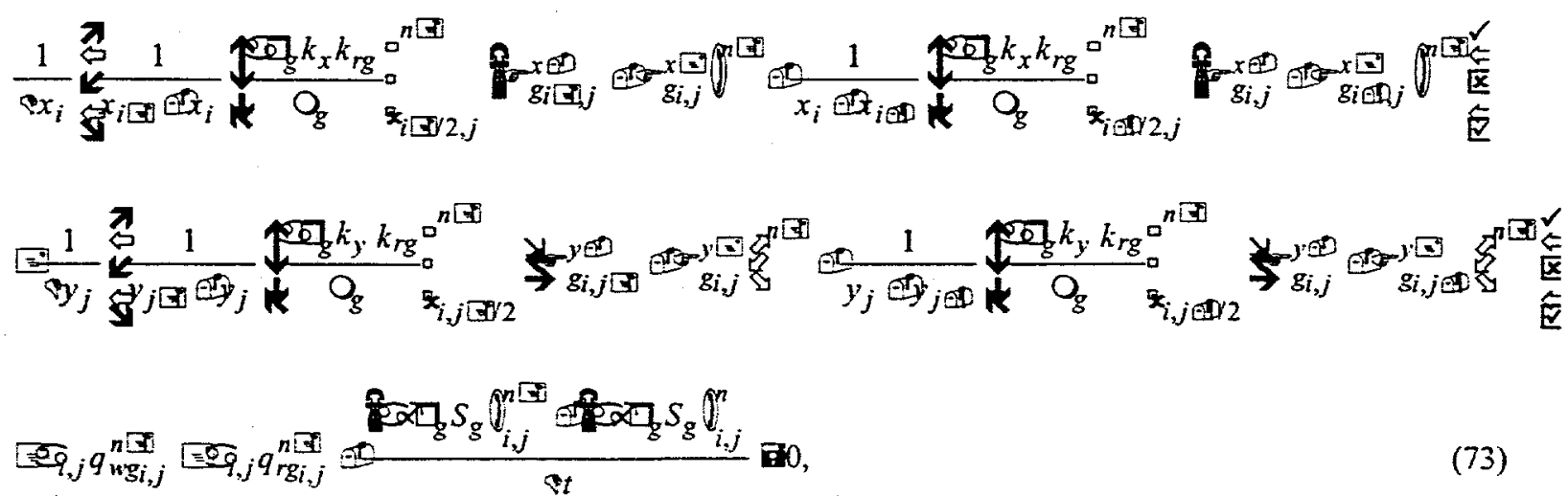

where $\Phi$ represents the phase potentials given by

$$
\begin{aligned}
& \Phi_{g i, j}^{x+}=p_{g i, j}+\rho_{g i+1 / 2, j} g h_{i, j}, \quad \Phi_{g i, j}^{x-}=p_{g i, j}+\rho_{g i-1 / 2, j} g h_{i, j} \\
& \Phi_{g i, j}^{y+}=p_{g i, j}+\rho_{g i, j+1 / 2} g h_{i, j}, \quad \Phi_{g i, j}^{y-}=p_{g i, j}+\rho_{g i, j-1 / 2} g h_{i, j}
\end{aligned}
$$

the subscripts are defined by $i=x$-direction grid index, $j=y$-direction grid index, $i \pm 1 / 2=x$-direction grid block interface, $j \pm 1 / 2=y$-direction grid block interface, $x_{i}=$ grid block center in the $x$-coordinate direction $(\mathrm{m}), y_{j}=$ grid block center in the $y$-coordinate direction $(\mathrm{m}), \Delta x_{i}=$ grid block length in the $x$-coordinate direction $(\mathrm{m})$, and $\Delta y_{j}=$ grid block length in the $y$-coordinate direction $(m)$; the superscripts are defined by $n=$ index in the time discretization, known solution time level, and $n+1=$ index in the time discretization, unknown solution time level; and the interblock densities are defined by

$$
\begin{aligned}
& \rho_{g i+1 / 2, j}=\frac{\Delta x_{i+1, j}}{\Delta x_{i, j}+\Delta x_{i+1, j}} \rho_{g i, j}+\frac{\Delta x_{i, j}}{\Delta x_{i, j}+\Delta x_{i+1, j}} \rho_{g i+1, j} \\
& \rho_{g i-1 / 2, j}=\frac{\Delta x_{i, j}}{\Delta x_{i-1, j}+\Delta x_{i, j}} \rho_{g, i-1}+\frac{\Delta x_{i-1, j}}{\Delta x_{i-1, j}+\Delta x_{i, j}} \rho_{g i, j} \\
& \rho_{g i, j+1 / 2}=\frac{\Delta y_{i, j+1}}{\Delta y_{i, j}+\Delta y_{i, j+1}} \rho_{g i, j}+\frac{\Delta y_{i, j}}{\Delta y_{i, j}+\Delta y_{i, j+1}} \rho_{g i, j+1} \\
& \rho_{g i, j-1 ; 2}=\frac{\Delta y_{i, j}}{\Delta y_{i, j-1}+\Delta y_{i, j}} \rho_{g i, j-1} \frac{\Delta y_{i, j-1}}{\Delta y_{i, j-1}+\Delta y_{i, j}} \rho_{g i, j} .
\end{aligned}
$$


The interface values of $k_{r g}$ in Eq. (73) are evaluated using upstream weighted values (i.e., the relative permeabilities at each grid block interface are defined to be the relative permeabilities at the center of the adjacent grid block that has the highest potential). Further, interface values for $\alpha \rho_{g} k_{x} / \mu_{g}$ and $\alpha \rho_{g} k_{y} / \mu_{g}$ are obtained by harmonic averaging of adjacent grid block values for these expressions. ${ }^{16}$

The discretization of the brine mass balance equation is obtained by replacing the subscript for gas, $g$, by the subscript for brine, $b$. As a reminder, $p_{g}$ and $S_{b}$ are replaced in the numerical implementation with the substitutions indicated in Fig. 4. For the 1996 WIPP PA, wells are not used in the conceptual model. Thus, the terms $q_{w g}$ and $q_{w b}$ are zero. For this analysis, the wellbore is not treated by a well model, but rather is explicitly modeled within the grid as a distinct material region (i.e., region 1 in Fig. 1).

The resultant coupled system of nonlinear brine and gas mass balance equations is integrated in time using the Newton Raphson method with upstream weighting of the relative permeabilities as previously indicated. The primary unknowns at each computational cell center are brine pressure and gas saturation.

\section{Gas and Brine Flow across Specified Boundaries}

The Darcy velocity vectors $\mathrm{v}_{\mathrm{g}}(x, y, t)$ and $\mathrm{v}_{b}(x, y, t)$ for gas and brine flow $\left(\left(\mathrm{m}^{3} / \mathrm{m}^{2}\right) / \mathrm{s}=\mathrm{m} / \mathrm{s}\right)$ are defined by the expressions

$$
\begin{aligned}
& \mathbf{v}_{g}(x, y, t)=\mathbf{K}_{g} k_{r g}\left(\nabla p_{g}+\rho_{g} g \nabla h\right) / \mu_{g} \\
& \mathbf{v}_{b}(x, y, t)=\mathbf{K}_{b} k_{r b}\left(\nabla p_{b}+\rho_{b} g \nabla h\right) / \mu_{b}
\end{aligned}
$$

in Eqs. (2) and (3). Values for $v_{g}$ and $v_{b}$ are obtained and saved as the numerical solution of Eqs. (2) - (7) is carried out. Cumulative flows of gas, $C_{g}(t, \mathrm{~B})$, and brine, $C_{b}(t, \mathrm{~B})$, from time 0 to time $t$ across an arbitrary boundary $\mathrm{B}$ in the domain of Eqs. (2) - (7) (i.e., Figs. 1 and 3) is then given by

$$
C_{l}(t, \mathrm{~B})=\int_{0}\left[\int_{\mathrm{B}} \alpha(x, y) \mathbf{v}_{l}(x, y, t) \cdot \mathrm{n}(x, y) d s\right] d t
$$

for $l=g, b$, where $\alpha(x, y)$ is the geometry factor defined in Fig. $2, \mathbf{n}(x, y)$ is an outward pointing unit normal vector,

and $\int_{\mathrm{B}} \dot{\sim} d s$ denotes a line integral. As an example, $\mathrm{B}$ could correspond to the boundary of the waste disposal regions in Fig. 1. The integrals defining $C_{g}(t, \mathrm{~B})$ and $C_{b}(t, \mathrm{~B})$ can be evaluated from results calculated and saved during the numerical solution of Eqs. (2) - (7). Due to the dependence of gas volume on pressure, $C_{g}(t, \mathrm{~B})$ is typically calculated in moles or in $\mathrm{m}^{3}$ at standard temperature and pressure, which requires an appropriate change of units for $v_{g}$ in Eq. (76). 


\section{Additional Information}

Additional information on BRAGFLO and its use in the 1996 WIPP PA can be found in the BRAGFLO users manual ${ }^{16}$ and in the analysis package for the Salado flow calculations. ${ }^{13}$

\section{Discussion}

The two-phase flow model, which is implemented by the BRAGFLO program, is the most complex and computationally intensive model incorporated into the 1996 WIPP PA. Directly or indirectly, this model supplies input to most of the remaining models used in the 1996 WIPP PA (i.e., spallings, ${ }^{2}$ direct brine release, ${ }^{3}$ transport in the vicinity of the repository, ${ }^{4}$ and transport in the Culebra Dolomite). ${ }^{5}$ Thus, the two-phase flow model implemented by the BRAGFLO program is the core model underlying the determination of radionuclide releases to the accessible environment in the 1996 WIPP PA.

The representation of two-phase flow in the 1996 WIPP PA and the computational implementation of this representation in the BRAGFLO program has received extensive review both internal to Sandia and by outside review groups. 53,54 In its review, the NEAIAEA International Review Group 54 stated: "The BRAGFLO model is state-of-the-art in two-phase, gas-brine modeling, and its application in performance assessment is in advance of practice in other countries."

Development work on the representation of two-phase flow by the BRAGFLO program is continuing as part of the WIPP PA program Current efforts include (i) an improved treatment of fluid flow in fractures within the anhydrite marker beds based on new data on fracture characteristics and failure properties of anhydrites, (ii) incorporation of a more realistic gas generation model that is coupled with the effects of MgO chemistry, (iii) incorporation of more efficient and robust numerical solution procedures to handle requirements associated with three-dimensional simulations and more detailed representations of fluid flow and chemistry, (iv) improvement of visualization capabilities, and (v) revision of the models for the DRZ.

Future work may also include addition of the capability of representing a drilling intrusion as a completed well (in essence, as a boundary value condition), which would allow the same computational grid to be used for both intruded and unintruded conditions. With this approach, the well would not be included in the computational grid, which would facilitate the solution of the system of nonlinear partial differential equations on which BRAGFLO is based. In particular, many of the numerical problems that arise in the use of BRAGFLO derive from the small computational grid blocks used in the representation of drilling intrusions. This change would also reduce the size of the computational grid and thus result in shorter run times for BRAGFLO.

This article has concentrated on the mathematical and computational representation of two-phase flow in the 1996 WIPP PA. Calculated results for two-phase flow are presented in two additional articles. ${ }^{6,7}$ 


\section{Acknowledgment}

Work performed for Sandia National Laboratories (SNL), which is a multiprogram laboratory operated by Sandia Corporation, a Lockheed Martin Company, for the United States Department of Energy under contract DE-AC04-94AL85000. Review provided at SNL by M. Chavez, C. Crawford and M.S. Tierney. Editorial support provided by L. Harrison, T. Allen and H. Radke of Tech Reps, Inc.

\section{References}

1. Helton, J.C., Anderson, D.R., Basabilvazo, G., Jow, H.-N., \& Marietta, M.G., Conceptual Structure of the 1996 Performance Assessment for the Waste Isolation Pilot Plant, Reliability Engineering and System Safety (in this issue).

2. Berglund, J.W., Garner, W., Helton, J.C., Johnson, J.D., \& Smith, L.N., Direct Releases to the Surface and Associated Complementary Cumulative Distribution Functions in the 1996 Performance Assessment for the Waste Isolation Pilot Plant: Cuttings, Cavings and Spallings, Reliability Engineering and System Safety (in this issue).

3. Stoelzel, D.M. O'Brien, D.G., Gamer, J.W., Helton, J.C., Johnson, J.D., \& Smith, L.N., Direct Releases to the Surface and Associated Complementary Cumulative Distribution Functions in the 1996 Performance Assessment for the Waste Isolation Pilot Plant: Direct Brine Release, Reliability Engineering and System Safety (in this issue).

4. Stockman, C.T., Garner, W., Helton, J.C., Johnson, J.D., Shinta, A., \& Smith, L.N., Radionuclide Transport in the Vicinity of the Repository and Associated Complementary Cumulative Distribution Functions in the 1996 Performance Assessment for the Waste Isolation Pilot Plant, Reliability Engineering and System Saffety (in this issue).

5. Ramsey, J.L., Blaine, R, Garner, J.W., Helton, J.C., Johnson, J.D., Smith, L.N., \& Wallace, M., Radionuclide and Colloid Transport in the Culebra Dolomite and Associated Complementary Cumulative Distribution Functions in the 1996 Performance Assessment for the Waste Isolation Pilot Plant, Reliability Engineering and System Safety (in this issue).

6. Helton, J.C., Bean. J.E., Economy, K., Garner, J.W., MacKinnon, R.J., Miller, J., Schreiber, J.D., \& Vaughn, P., Uncertainty and Sensitivity Analysis for Two-Phase Flow in the Vicinity of the Repository in the 1996 Performance Assessment for the Waste Isolation Pilot Plant: Undisturbed Conditions, Reliability Engineering and System Safety (in this issue).

7. Helton, J.C., Bean. J.E., Economy, K., Garner, J.W., MacKinnon, R.J., Miller, J., Schreiber, J.D., \& Vaughn, P., Uncertainty and Sensitivity Analysis for Two Phase Flow in the Vicinity of the Repository in the 1996 Performance Assessment for the Waste Isolation Pilot Plant: Disturbed Conditions, Reliability Engineering and System Safety (in this issue).

8. Helton, J.C., Bean. J.E., Berglund, J.W., Davis, F.J., Economy, K., Garner, J.W., Johnson, J.D., MacKinnon, R.J., Miller, J., O'Brien, D.G., Ramsey, J.L., Schreiber, J.D. Shinta, A., Smith, L.N., Stoelzel, D.M., Stockman, C., \& Vaughn. P., Uncenainty and Sensitivity Analysis Results Obtained in the 1996 Performance Assessment for the Waste Isolation Pilot Plant, SAND98-0365, Sandia National Laboratories, Albuquerque, NM, 1998.

9. Brooks, R.H. \& Corey, A.T., Hydraulic Properties of Porous Media, Hydrology Paper No. 3, Colorado State University, Fort Collins, CO, 1964. 
10. Webb, S.W., Appendix A: Uncertainty Estimates for Two-Phase Characteristic Curves for 199240 CFR 191 Calculations, Preliminary Performance Assessment for the Waste Isolation Pilot Plant. December 1992. Volume 3: Model Parameters, Sandia WIPP Project, SAND92-0700/3, Sandia National Laboratories, Albuquerque, NM, A-147 through A-155, 1992.

11. Helton, J.C., Martell, M.-A., \& Tierney, M.S., Characterization of Subjective Uncertainty in the 1996 Performance Assessment for the Waste Isolation Pilot Plant, Reliability Engineering and System Safety (in this issue).

12. Martell, M.A., Additional Information for the DRZ (Disturbed Rock Zone) Porosity, Memo to C. Lattier, November 14, 1996, WIPP Central Files WPO \# 42257, Sandia National Laboratories, Albuquerque, NM.

13. Bean, J.E., Lord, M.E., McArthur, D.A., MacKinnon, R.J., Miller, J.D., \& Schreiber, J.D, Analysis Package for the Salado Flow Calculations (Task 1) of the Performance Assessment Analysis Supporting the Compliance Cerification Application), Sandia WIPP Central Files WPO \# 40514, Sandia National Laboratories, Albuquerque, NM, 1996.

14. Helton, J.C., Davis, F.J., \& Johnson, J.D., Characterization of Stochastic Uncertainty in the 1996 Performance Assessment for the Waste Isolation Pilot Plant, Reliability Engineering and System Safety (in this issue).

15. van Genuchten, R., Calculating the Unsaturated Hydraulic Conductivity with a New Closed Form Analytical Model, Research Report 78-WR-08, Princeton University; Dept of Civil Engineering, Princeton, NJ, 1978.

16. WIPP PA, BRAGFLO, Version 4.00, User's Manual, Sandia WIPP Central Files WPO \# 30703, Sandia National Laboratories, Albuquerque, NM, 1996.

17. Howarth, S.M. \& Christian-Frear, T., Porosity, Single-Phase Permeability, and Capillary Pressure Data from Preliminary, Laboratory Experiments on Selected Samples from Marker Bed 139 at the Waste Isolation Pilot Plant, Records package, Sandia WIPP Central Files WPO \# 38019, Sandia National Laboratories, Albuquerque, NM, 1996.

18. Klinkenberg, L.J., The Permeability of Porous Media to Liquids and Gases, Drilling and Production Practice, American Petroleum Institute, New York, NY, 1941, 200-213.

19. Christian-Frear, T.L., Salado Halite Permeability from Room Q Analysis, Records package, Sandia WIPP Central Files WPO \# 30721, Sandia National Laboratories, Albuquerque, NM, 1996.

20. Walas, S.M., Phase Equilibria in Chemical Engineering, Butterworth Publishers, Boston, MA, 1985.

21. Graboski, M.S. \& Daubert, T.E., A Modified Soave Equation of State for Phase Equilibrium Calculations, 3: Systems Containing Hydrogen, Industrial and Engineering Chemistry. Process Design and Development, 1979, $18,300-306$.

22. Prausnitz, J.M., Molecular Thermodynamics of Fluid - Phase Equilibria, Prentice-Hall, Englewood Cliffs, NJ, 1969.

23. Weast. R.C., ed., Handbook of Chemistry and Physics, 50th ed., Chemical Rubber Co., Cleveland, OH, 1969.

24. Roberts, R., Salado: Brine Compressibility, Records Package, Sandia WIPP Central Files WPO $¥ 31174$, Sandia National Laboratories, Albuquerque, NM, 1996.

25. Vargaftik. N.B., Tables on the Thermophysical Properties of Liquids and Gases in Normal and Dissociated States, $2^{\text {nd }}$ edition. Hemisphere Pub. Corp., Washington, DC; Halstead Press (dist.), New York, NY, 1975. 
26. McTigue, D.F., Permeability and Hydraulic Diffusivity of Waste Isolation Pilot Plant Repository Salt Inferred from Small-Scale Brine Inflow Experiments, SAND92-1911, Sandia National Laboratories, Albuquerque, NM, 1993.

27. WIPP PA (Performance Assessment), Preliminary Performance Assessment for the Waste Isolation Pilot Plant, December 1992, SAND92-0700/1-5, Volumes 1-5, Sandia National Laboratories, Albuquerque, NM, 19921993.

28. Kelley, V.A., Jones, T.L., \& Ogintz, J.B., WPP Seal System Parameters for Performance Assessment BRAGFLO Compliance Calculations, Memo to D. Hurtado, Jan. 15, 1996, Sandia WIPP Central Files WPO \# 30995, Sandia National Laboratories, Albuquerque, NM, 1996.

29. Kelley, V.A., Jones, T.L., \& Ogintz, J.B., WIPP Shaft Seal System Parameters Documentation to Support Performance Assessment BRAGFLO Compliance Calculations, Memo to L.D. Hurtado, March 22, 1996, Sandia WIPP Central Files WPO \# 40258, Sandia National Laboratories, Albuquerque, NM, 1996.

30. U.S. Department of Energy, Waste Isolation Plant Sealing System Design Report, DOE/WIPP-95-3117, U.S. Department of Energy, Waste Isolation Pilot Plant, Carlsbad Area Office, Carlsbad, NM, 1995.

31. Stone, C.M., SANTOS - A Two-Dimensional Finite Element Program for the Quasistatic. Large Deformation, Inelastic Response of Solids, SAND90-0543, Sandia National Laboratories, Albuquerque, NM, 1997.

32. Stone, C.M., Final Disposal Room Structural Response Calculations, SAND97-0795, Sandia National Laboratories, Albuquerque, NM, 1997.

33. Freeze, G.A., Larson, K.W., \& Davies, P.B., Coupled Multiphase Flow and Closure Analysis of Repository Response to Waste-Generated Gas at the Waste Isolation Pilot Plant (WIPP), SAND93-1986, Sandia National Laboratories, Albuquerque, NM, 1995.

34. Mendenhall, F.T., WIPP Anhydrite Fracture Modeling, Memo, December 6, 1993, Sandia WIPP Central Files WPO \# 39830, Sandia National Laboratories, Albuquerque, NM, 1993.

35. Lide, D.E. (Ed.)., CRC Handbook of Chemistry and Physics, 72 edn., CRC Press, Boca Raton, FL, 1991.

36. Telander, M.R., \& Westerman, R.E., Hydrogen Generation by Metal Corrosion in Simulated Waste Isolation Pilot Plant Environments: Progress Report for the Period November 1989 Through December 1992, SAND92-7347, Sandia National Laboratories, Albuquerque, NM, 1993.

37. WIPP PA (Performance Assessment), Preliminary Comparison with 40 CFR Part 191, Subpart B for the Waste Isolation Pilot Plant, December 1991, SAND91-0893/1-4, Volumes 1-4, Sandia National Laboratories, Albuquerque, NM, 1991-1992.

38. Schreiber, J., Hand calculation. Attached to Form 464 for REFCON VREPOS, ID\# 3108, Sandia WIPP Central Files WPO\# 33276, 7/29/91 and 8/12/91, Sandia National Laboratories, Albuquerque, NM, 1991.

39. Nowak, E.J., Tillerson, J.R., \& Torres, T.M., Initial Reference Seal System Design: Waste Isolation Pilot Plant, SAND90-0355, Sandia National Laboratories, Albuquerque, NM, 1990.

40. Bechtel National, Inc., Waste Isolation Pilot Plant Design Validation Report, DOE/WIPP-86-010. Prepared for the U.S. Department of Energy, Bechtel National, Inc., San Francisco, CA, 1986.

41. Francis, A.J., Gillow, J.B., \& Giles, M.R., Microbial Gas Generation under Expected WIPP Repository Conditions. SAND96-2582, Sandia National Laboratories, Albuquerque, NM, 1997. 
42. Wang Y. \& Brush, L., Modify the Stoichiometric Factor $y$ in BRAGFLO to Include the Effect of MgO Added to WIPP Repository as a Bachfill, Memo to M. Tiemey, Feb. 23, 1996.

43. U.S. Department of Energy, Transuranic Waste Baseline Inventory Report, DOE/CAO-95-1121, Revision 2, U.S. Department of Energy, Carlsbad Area Office, Carlsbad, NM, December 1995.

44. Telander, M.R., \& Westerman, R.E., Hydrogen Generation by Metal Corrosion in Simulated Waste Isolation Pilot Plant Environments, SAND96-2538, Sandia National Laboratories, Albuquerque, NM, 1997.

45. Haberman, J.H. \& Frydrych, D.J., Corrosion Studies of A216 Grade WCA Steel in Hydrothermal MagnesiumContaining Brines, Scientific Basis for Nuclear Waste Management XI, Materials Research Society Symposium Proceedings, Boston, MA, November 30 - December 3, 1987. Eds. M.J. Apted and R.E. Westerman. Pittsburgh, PA: Materials Research Society, 1988, 112, 761-772.

46. Wang, Y. \& Brush, L., Estimates of Gas-Generation Parameters for the Long-Term WIPP Performance Assessment, Memo to M. Tierney, Jan. 26, 1996, Sandia WIPP Central Files WPO \# 35162, Sandia National Laboratories, Albuquerque, NM, 1996.

47. Bynum, R.V., Stockman, C., Wang, Y., Peterson, A., Krumhansl, J., Nowak, J., Chu, M.S.Y., Cotton, J., \& Patchett, S.J., Implementation of Chemical Controls through a Backfill System for the Waste Isolation Pilot Plant (WIPP), Proceedings of the Sixth International Conference on Radioactive Waste Management and Environmental Remediation, ICEM '97, Singapore, October 12-16, 1997, SAND96-2656C. Eds. R. Baker, S. Slate, and G. Benda, New York, NY, American Society of Mechanical Engineers, 357-361, 1997.

48. U.S. Department of Energy, Title 40 CFR Part 191 Compliance Certification Application for the Waste Isolation Pilot Plant, DOE/CAO-1996-2184, Volumes I-XXI, U.S. Department of Energy, Carlsbad Area Office, Carlsbad, NM, 1996.

49. Drez, P., Preliminary Estimate for SNLNM Performance Assessment Calculations of Nitrate, Sulfate, and Phosphate Content in Transuranic Solidified Wastes Destined for Disposal in WIPP, Carlsbad Technical Assistance Contractors. Memo, 1/26/96. Reproduced as memorandum from D. Watkins to L. Shephard dated Feb. 20, 1996, in App. B-6 of U.S. Department of Energy. Transuranic Waste Baseline Inventory Report (Revision 3), DOE/CAO-95-1121, Revision 3, U.S. Department of Energy, Carlsbad Area Office, Carlsbad, NM, 1996.

50. Thompson, T.W., Coons, W.E., Krumhansl, J.L., \& Hansen, F.D., Inadvertent Intrusion Borehole Permeability, Final Draft, August 1, 1996, Sandia WIPP Central Files WPO \# 41131, Sandia National Laboratories, Albuquerque, NM, 1996.

51. Vaughn, P., Salado Borehole Diameter, Memo from P. Vaughn to M. Tierney, Feb. 23, 1996. Sandia WIPP Central Files WPO \$35329, Sandia National Laboratories, Albuquerque, NM, 1996.

52. Howard, B.A., Performance Assessment Parameter Input. Memo from B.A. Howard to M. Marietta, February 23, 1996, Sandia WIPP Central Files WPO \# 47595, Westinghouse Electric Corporation, Carlsbad, NM. Sandia National Laboratories, Albuquerque, NM, 1996.

53. Wilson, C., Porter, D., Gibbons, B., Oswald, E., Sjoblem, G., \& Caporuscio, F., Final Waste Isolation Pilot Plant Conceptual Models Peer Review Report (July 1996, Sandia WIPP Central Files WPO \#41805). Waste Isolation Pilot Plant Conceptual Models Supplementary Peer Review Report (December 1996, Sandia WIPP Central Files WPO \#43153). Waste Isolation Pilot Plant Second Supplementary Peer Review Report (January 1997, Sandia WIPP Central Files WPO \#44536). U.S. Department of Energy, Carlsbad Area Office, Office of Regulatory Compliance, Carlsbad, NM, 1996-1997. 
54. IRG (International Review Group), International Peer Review of the 1996 Performance Assessment of the U.S. Waste lsolation Pilot Plant (WIPP), April 1997. Report of the NEA/AEA International Review Group, Paris, France: Nuclear Energy Agency/International Atomic Energy Agency Joint Secretariat. Sandia WIPP Central Files WPO \#49347, Sandia National Laboratories, Albuquerque, NM, 1997. 
Figure Captions

Fig. 1. Computational grid used in BRAGFLO to represent two phase flow in 1996 WIPP PA subsequent to a drilling intrusion. Same formulation is used in the absence of a drilling intrusion except that regions $1 \mathrm{~A}, 1 \mathrm{~B}$ and $\mathrm{IC}$ have the same properties as the regions to either side.

Fig. 2. Definition of element depth (i.e., element thickness normal to flow plane) in computational implementation of two-phase flow in 1996 WIPP PA. Cells 1 to 33 correspond to the 33 grid cells indicated in the $x$ direction in Fig. 1; the indicated depths of these cells define the factor $\alpha$ in Eqs. (2) and (3).

Fig. 3. Identification of individual cells in computational grid used with BRAGFLO to represent two phase flow in 1996 WIPP PA.

Fig. 4. Reduction of gas and brine conservation equations to system of two equations in two unknowns (i.e., $S_{g}$ and $p_{b}$ ) for numerical solution.

Fig. 5. Conceptual representation of shaft-seal system used in definition of model parameters for use in conjunction with regions $3-11$ of Fig. 2.

Fig. 6. Disposal room pressure for different values of the gas generation scale factor $(f)$. Individual curves correspond to the functions $p(t, f)$ in Eq. (39) and were obtained from calculations performed with SANTOS.

Fig. 7. Disposal room porosity curves for different values of the gas generation scale factor $(f)$. Individual curves correspond to the functions $\phi(t, f)$ in Eq. (41) and define porosities for use in BRAGFLO on the basis of calculations performed with SANTOS. 


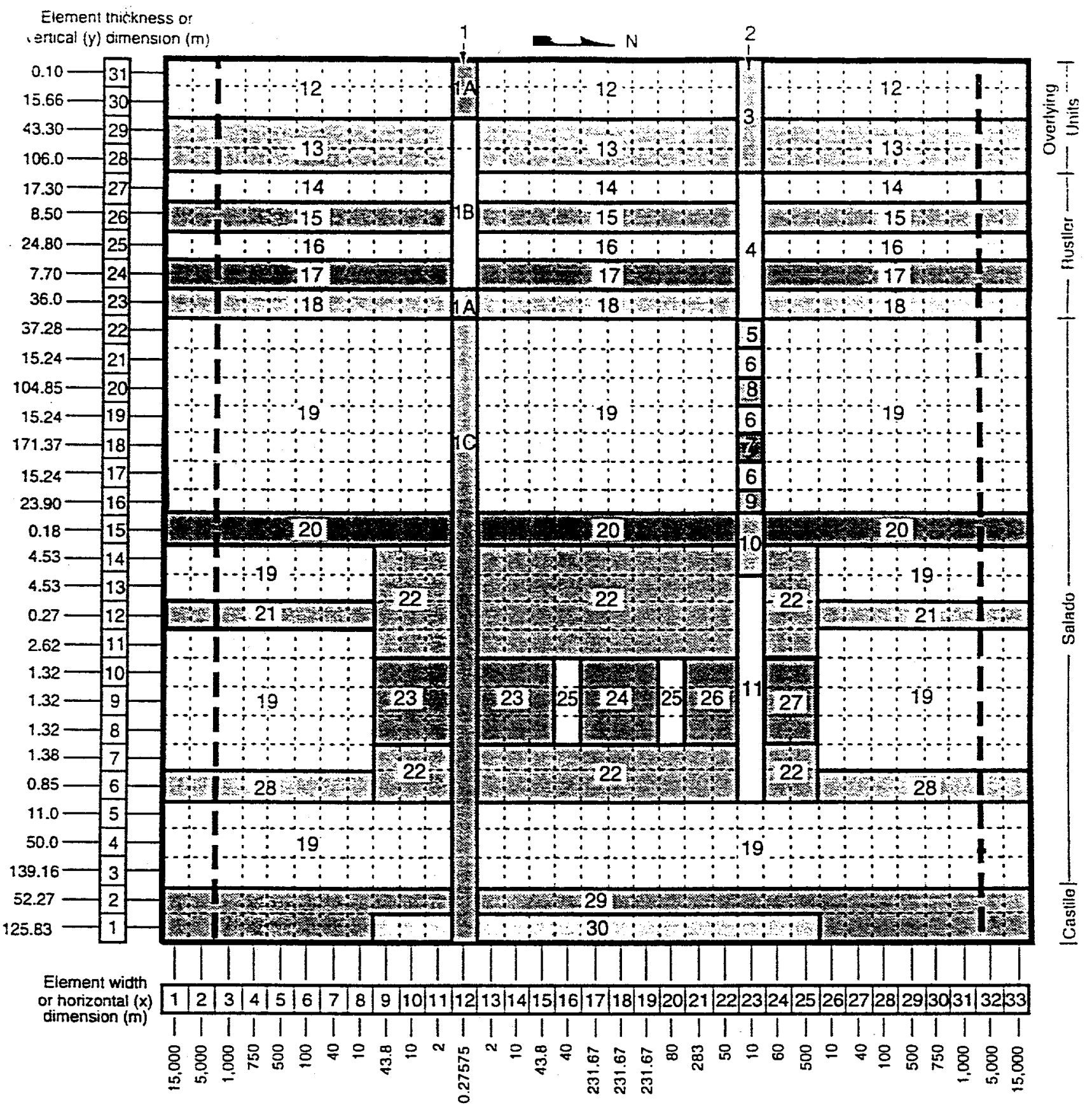

8. Upper Salado compacted clay column
9. Lower Salado compacted clay column
10. Lower clay component
11. Concrete monolith
12. Units above the Dewey Lake
13. Dewey Lake
14. Forty-niner
15. Magenta
16. Tamarisk
17. Culebra
18. Unnamed lower member
19. Impure halite

\author{
20. MB138 \\ 21. Anhydrite layer $a$ and $b$ \\ 22. Disturbed rock zone . \\ 23. Waste panel \\ 24. Rest of repository \\ 25. Panel closures \\ 26. Operation region \\ 27. Experimental area \\ 28. MB139 \\ 29. Castile \\ 30. Brine reservoir
}

Fig. 1. Computational grid used in BRAGFLO to represent two phase flow in 1996 WIPP PA subsequent to a drilling intrusion. Same formulation is used in the absence of a drilling intrusion except that regions $1 \mathrm{~A}$. 1B and $1 \mathrm{C}$ have the same properties as the regions to either side. 


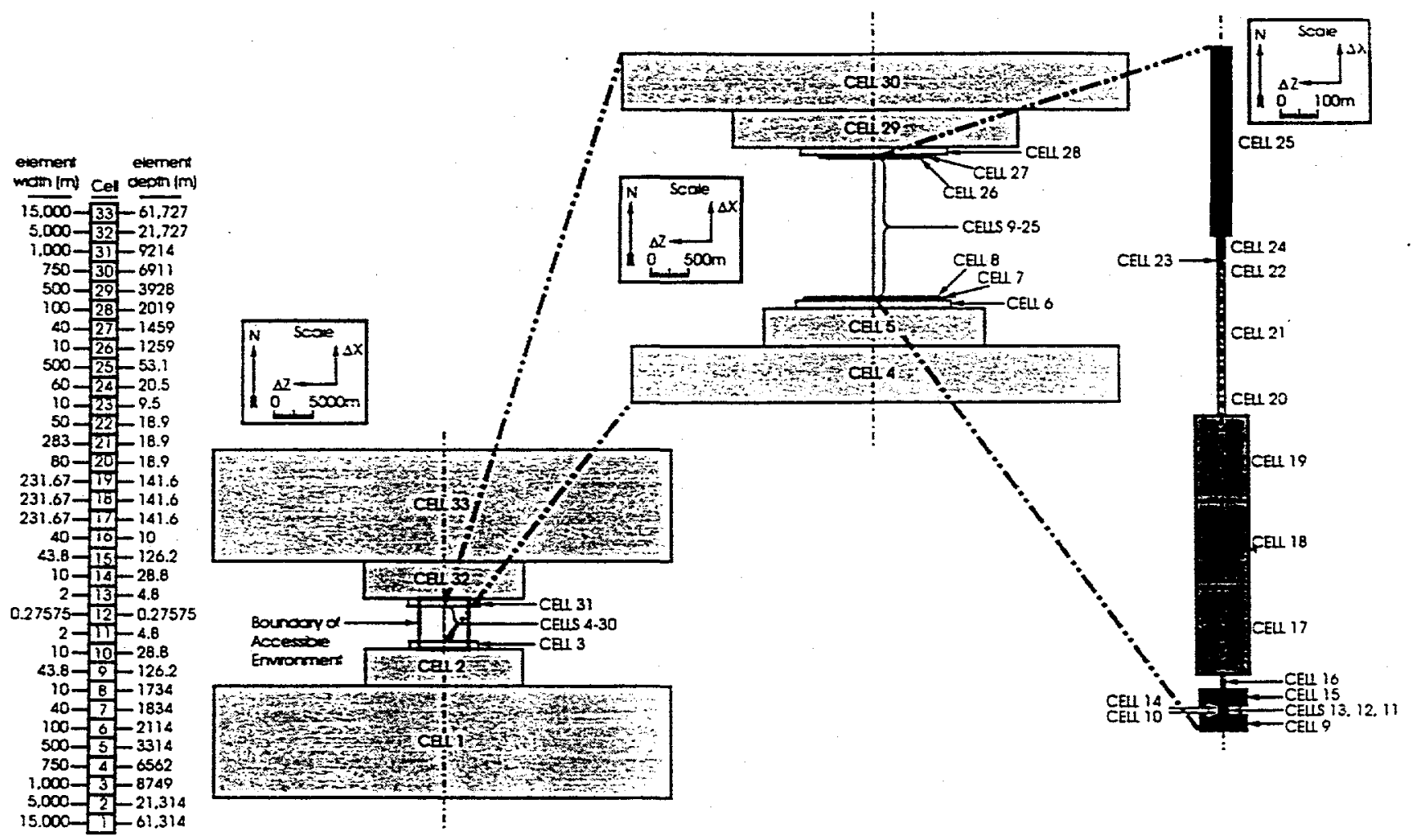

$\pi R-6342-5242 \cdot 060$

Fig. 2. Definition of element depth (i.e., element thickness normal to flow plane) in computational implementation of two-phase fiow in 1996 WIPP PA. Cells 1 to 33 correspond to the 33 grid cells indicated in the $x$ direction in Fig. 1; the indicated depths of these cells define the factor $\alpha$ in Eqs. (2) and (3). 


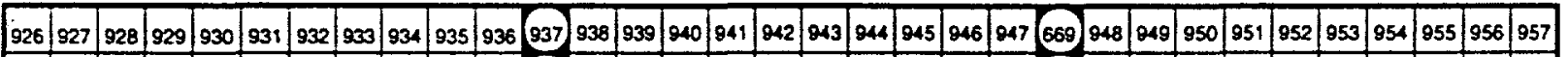

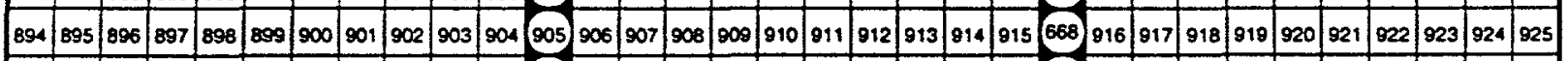

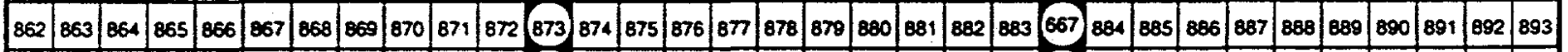

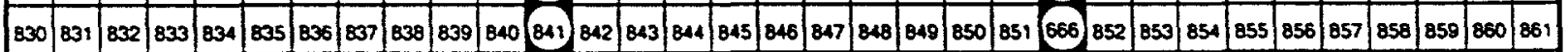

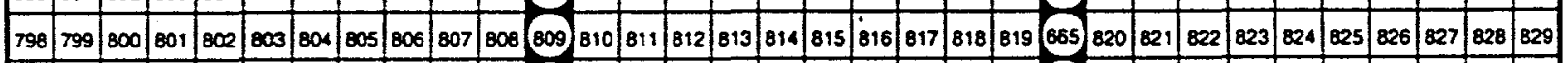

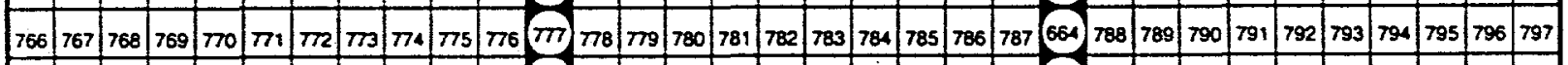

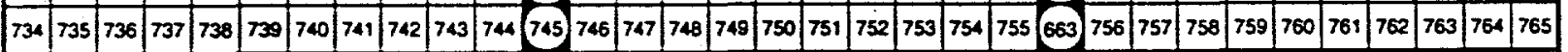

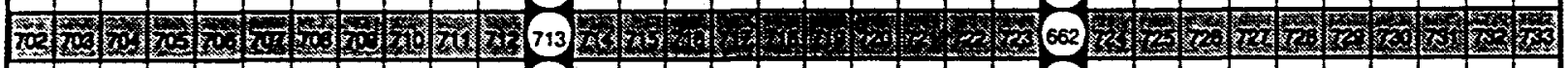

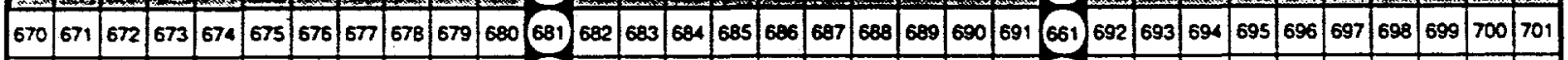

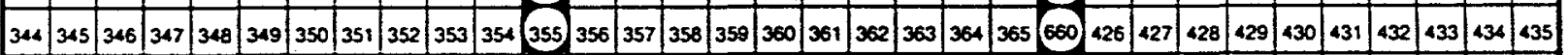

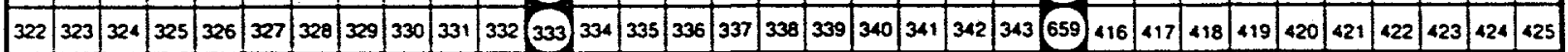

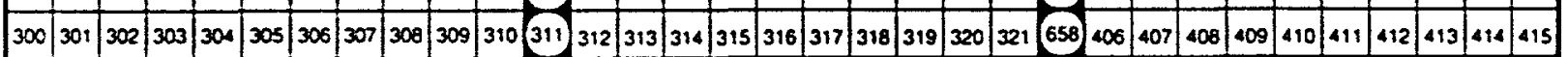

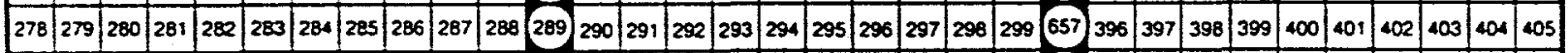

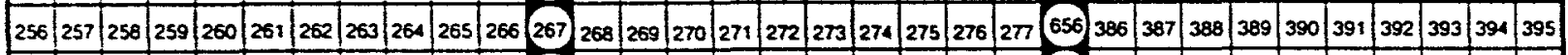

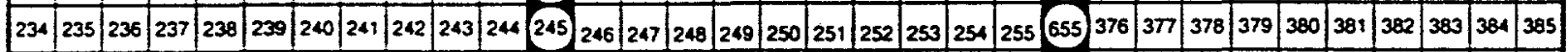

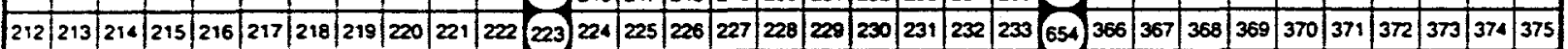

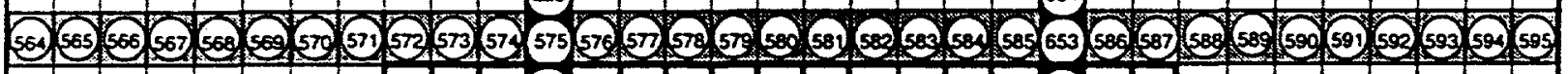

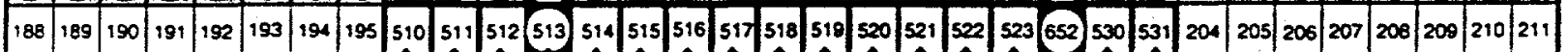

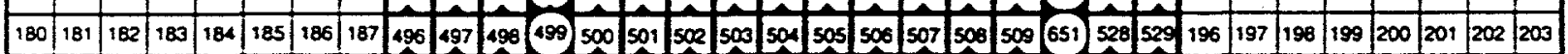

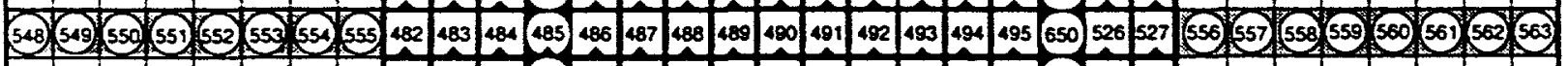

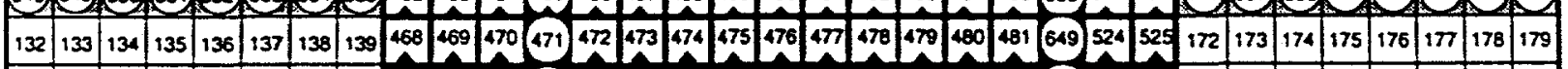

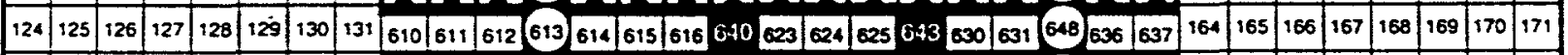

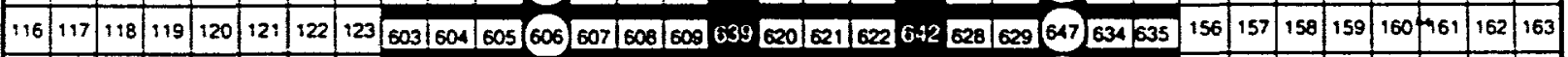

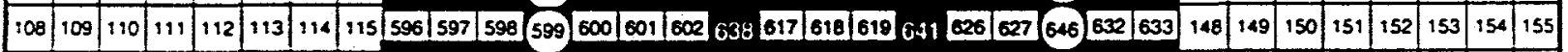

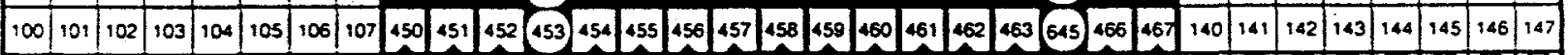

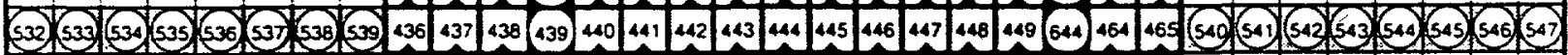
\begin{tabular}{|l|l|l|l|l|l|l|l|l|l|l|l|l|l|l|l|l|l|l|l|l|l|l|l|l|l|l|l|l|l|l|l|l|}
\hline 67 & 68 & 69 & 70 & 71 & 72 & 73 & 74 & 75 & 76 & 77 & 78 & 79 & 80 & 81 & 82 & 83 & 84 & 85 & 86 & 87 & 88 & 89 & 90 & 91 & 92 & 93 & 94 & 95 & 96 & 97 & 98 & 99 \\
\hline
\end{tabular} \begin{tabular}{|l|l|l|l|l|l|l|l|l|l|l|l|l|l|l|l|l|l|l|l|l|l|l|l|l|l|l|l|l|l|l|l|l|l|}
\hline 34 & 35 & 36 & 37 & 38 & 39 & 40 & 41 & 42 & 43 & 44 & 45 & 46 & 47 & 48 & 49 & 50 & 51 & 52 & 53 & 54 & 55 & 56 & 57 & 58 & 59 & 60 & 61 & 62 & 63 & 64 & 65 & 66 & 5 \\
\hline
\end{tabular} \begin{tabular}{|l|l|l|l|l|l|l|l|l|l|l|l|l|l|l|l|l|l|l|l|l|l|l|l|l|l|l|l|l|l|l|l|l|}
\hline 1 & 2 & 3 & 4 & 5 & 6 & 7 & 8 & 9 & 10 & 11 & 12 & 13 & 14 & 15 & 16 & 17 & 16 & 19 & 20 & 21 & 22 & 23 & 24 & 25 & 26 & 27 & 28 & 29 & 30 & 31 & 32 & 33 \\
\hline
\end{tabular}

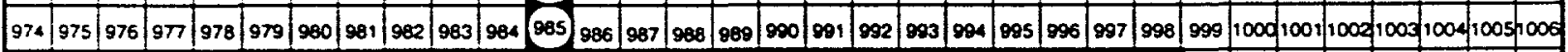

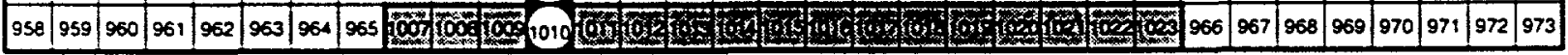

Borehole (left), shaft (right)

Panel Seals

Excavated Areas
Anhydrite marker Beds

Disturbed Rock Zone (DRZ)

Culebra (upper), Brine Pocket (lower)

Fig. 3. Identification of individual cells in computational grid used with BRAGFLO to represent two phase flow in 1996 WIPP PA. 


\section{Gas Conservation}

$\nabla \cdot\left[\frac{\alpha \rho_{g} K_{g} k_{r g}}{\mu_{g}}\left(\nabla_{p_{g}}+\rho_{g} g \nabla h\right)\right]+\alpha q_{w^{\prime} g}+\alpha q_{r g}=\alpha \frac{\partial\left(\phi \rho_{g} S_{g}\right)}{\partial t}$

Brine Conservation

$$
\begin{gathered}
S_{b}=1-S_{g} \text { (see Eq. 4) } \\
\nabla \cdot\left[\frac{\alpha \rho_{b} K_{b} k_{r b}}{\mu_{b}}\left(\nabla p_{b}+\rho_{b} g \nabla h\right)\right]+\alpha q_{w b}+\alpha q_{r b}=\alpha \frac{\partial\left(\phi \rho_{b} S_{b}\right)}{\partial t}
\end{gathered}
$$

Fig. 4. Reduction of gas and brine conservation equations to system of two equations in two unknowns (i.e.., $S_{g}$ and $\left.p_{b}\right)$ for numerical solution. 


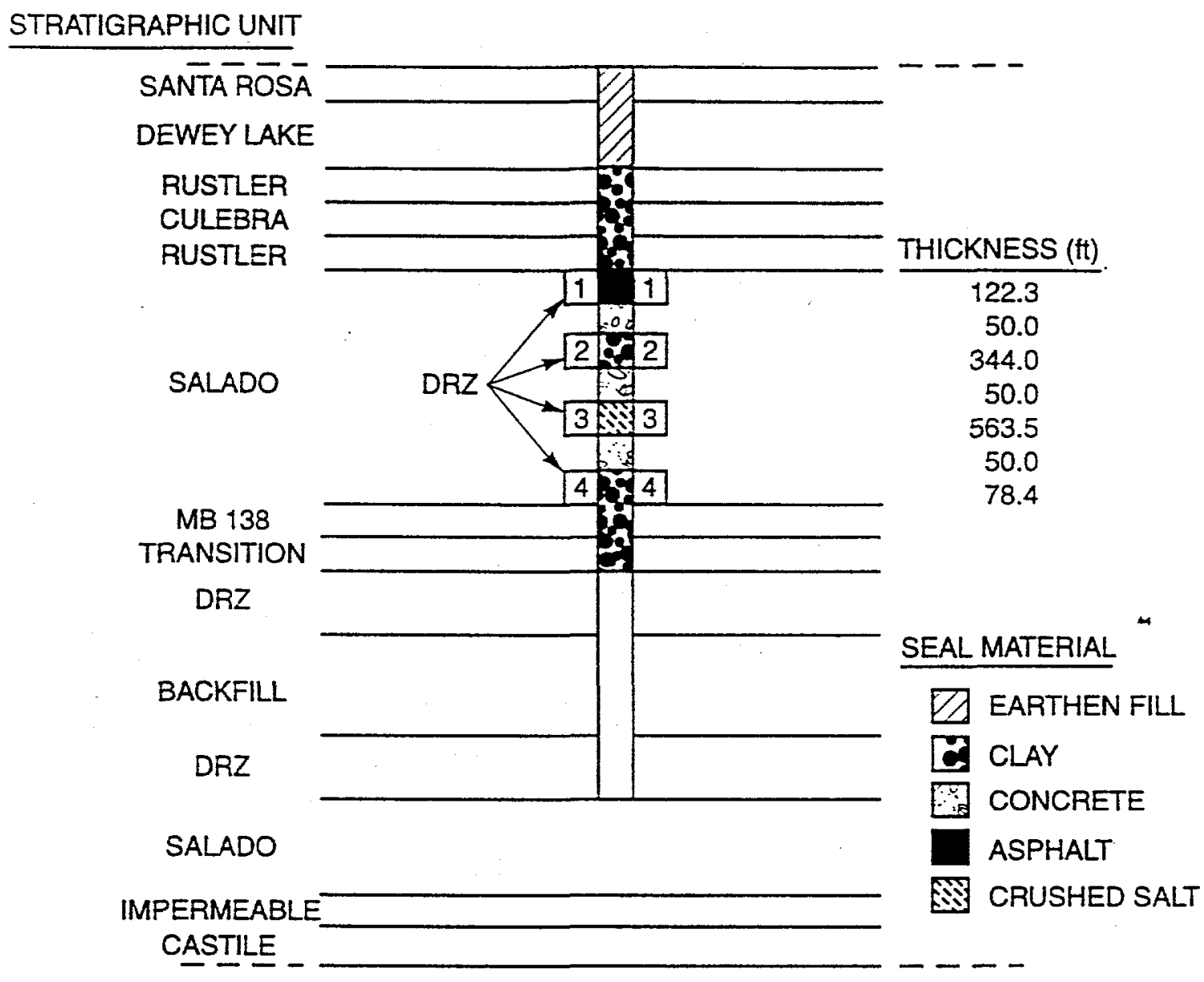

TA1-6342.5170-0

Fig. 5. Conceptual representation of shaft-seal system used in definition of model parameters for use in conjunction with regions $3-11$ of Fig. ?. 


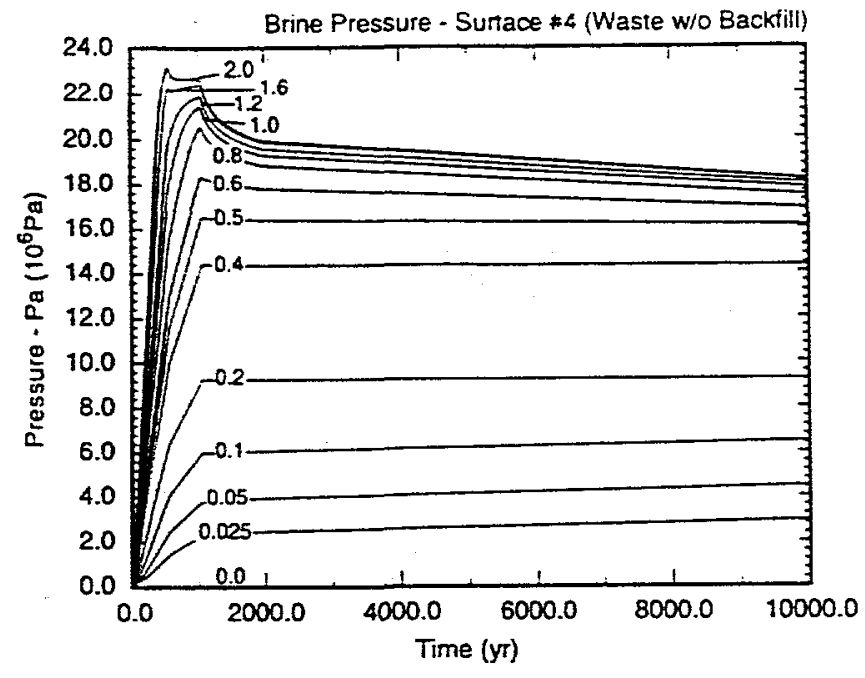

TRI-6342-5171-0

Fig. 6. Disposal room pressure for different values of the gas generation scale factor $(f)$. Individual curves correspond to the functions $p(t, f)$ in Eq. (39) and were obtained from calculations performed with SANTOS.

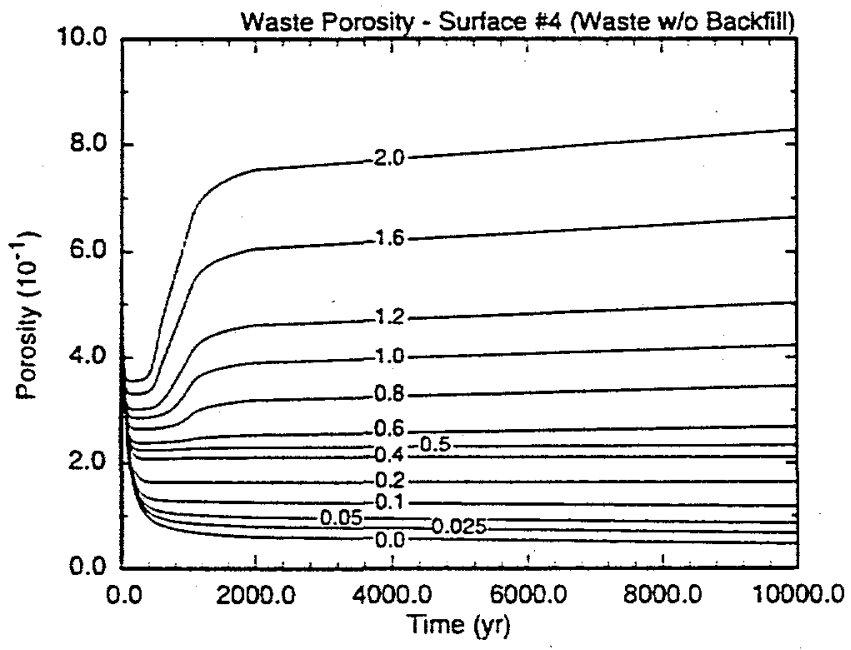

TR1-6342-5172-0

Fig. 7. Disposal room porosity curves for different values of the gas generation scale factor $(f)$. Individual curves correspond to the functions $\phi(t, f)$ in Eq. (41) and define porosities for use in BRAGFLO on the basis of calculations performed with S.ANTOS. 
Table 1. Parameter Values Used in Representation of Two Phase Flow

\begin{tabular}{|c|c|c|c|c|c|c|c|c|}
\hline Material: $1 ; R ; N^{i}$ & Material Description & $\lambda$ & $n$ & $\eta$ & $s_{b r}$ & $s_{g r}$ & $\phi_{0}$ & $\beta_{f}$ \\
\hline $1: 2 ; S$ HALIT: & Undisturbed Salado lim hatite & 0.7 & 0.56 & -0.346 & 0.3 & 0.2 & IIALPOR & $f\left(I / A L C O M P^{b}\right)^{d}$ \\
\hline $2 ; 22 ; \mathrm{DPR} Z \mathbf{0}$ & Disturbed rock zone, $-5 \cdot 0 \mathrm{yr}$ & 0.7 & 0.0 & 0.0 & 0.0 & 0.0 & $f(H A L P O R)^{c}$ & $6.286054 \times 10^{-8}$ \\
\hline $3 ; 28 ; S_{-} M 13139$ & MB3 1.39 in Sulado lim & $A N I B C E X 7^{b}$ & 0.26 & -0.348 & ANRBSAA & ANRGSSAT & 0.01 & $\int\left(A N / C O M I^{b}\right)^{d}$ \\
\hline $4 ; 21 ; S \_A N I I \_A B$ & Anhydrite layers $a \& b$ in Salado $\mathrm{Fm}$ & $A N H B C E X P^{h}$ & 0.26 & -0.348 & ANRBSA $7^{\mathrm{b}}$ & ANRGSSA $7^{\mathrm{b}}$ & 0.01 & $f\left(A N H C O M P^{b}\right)^{d}$ \\
\hline $5 ; 20 ; S \_M B 138$ & MB 138 in Salado $\mathrm{Fm}$ & ANHBCEXP & 0.26 & -0.348 & $A N R B S A 7^{6}$ & ANRGSSA $T^{\mathrm{b}}$ & 0.01 & $f\left(A N H C O M P^{\mathrm{b}}\right)^{\mathrm{d}}$ \\
\hline $0 ; 23 ;$ CAVITY_I $_{3}$ & Excavated waste panel, $-5-0 \mathrm{yr}$ & 0.7 & 0.0 & 0.0 & 0.0 & 0.0 & 1.0 & 0.0 \\
\hline $7 ; 24 ; C_{A V I T Y \_2}$ & Excavated rest of repository, $-5 \cdot 0 \mathrm{yr}$ & 0.7 & 0.0 & 0.0 & 0.0 & 0.0 & 1.0 & 0.0 \\
\hline $8 ; 26 ;$ CAVITY_3 $_{3}$ & Excavated operations \& exp'tl region, -5 - 0 yr & 0.7 & 0.0 & 0.0 & 0.0 & 0.0 & 1.0 & 0.0 \\
\hline $9 ; 27 ;$ CAVITY_4 $_{4}$ & lixcavated shaft and panel closures, $-5.0 \mathrm{yr}$ & 0.7 & 0.0 & 0.0 & 0.0 & 0.0 & 1.0 & 0.0 \\
\hline $10 ; 29 ;$ IMPERM_Z & Castile l'm impermeable material & 0.7 & 0.0 & 0.0 & 0.0 & 0.0 & 0.005 & 0.0 \\
\hline $11 ; 30 ; C A S T I L E R$ & Castile Fm brine reservoir & 0.7 & 0.56 & -0.340 & 0.2 & 0.2 & $f(B P V O L)^{e}$ & $f\left(B P C O M P^{l}\right)^{\mathrm{d}}$ \\
\hline $12 ; 23 ; W \wedge S \_A R E A$ & Single waste panel in repository & 2.89 & 0.0 & 0.0 & WRBRNSA $7^{\mathrm{b}}$ & WRGSSAT $T^{\mathrm{b}}$ & 0.848 & 0.0 \\
\hline 13; 24; REPOSIT & Rest of waste repository (minus one panel) & 2.89 & 0.0 & 0.0 & WRBRNSAT ${ }^{\mathrm{b}}$ & WRGSSAT & 0.848 & 0.0 \\
\hline $14 ; 18 ;$ UNNAMED & Unnamed Mbr of Rustler Fm & 0.7 & 0.0 & 0.0 & 0.2 & 0.2 & 0.181 & 0.0 \\
\hline 15: 17: CULEBRA & Culebra Mbr of Rustler Fm & 0.6436 & 0.26 & -0.348 & 0.08363 & 0.07711 & 0.151 & $6.622517 \times 10^{-10}$ \\
\hline $16 ; 16 ;$ TAMARISK & Tamarisk Mbr of Rustler Fm & 0.7 & 0.0 & 0.0 & 0.2 & 0.2 & 0.064 & 0.0 \\
\hline 17:15; MAGENTA & Magenta Mbr of Rustler $\mathrm{Fm}$ & 0.6436 & 0.26 & -0.348 & 0.08363 & 0.07711 & 0.138 & $1.915942 \times 10^{-9}$ \\
\hline 18;14; FORTYYIN & Fortyniner Mbr of Rustler Fm & 0.7 & 0.0 & 0.0 & 0.2 & 0.2 & 0.082 & 0.0 \\
\hline $19 ; 13 ;$ DEWYLAKE & Dewey Lake Redbeds & 0.6436 & 0.0 & 0.0 & 0.08363 & 0.07711 & 0.143 & $6.993007 \times 10^{-8}$ \\
\hline 20; 12: SANTAROS & Santa Rosa Fm & 0.6436 & 0.0 & 0.0 & 0.08363 & 0.07711 & 0.175 & $5.714286 \times 10^{-8}$ \\
\hline $21 ; 26 ;$ OPS_AREA & Excavated region between shafts \& repository & 0.7 & 0.0 & 0.0 & 0.0 & 0.0 & 0.18 & 0.0 \\
\hline $22 ; 27 ; E X X P \_A R E A$ & Excavated region north of shafts & 0.7 & 0.0 & 0.0 & 0.0 & 0.0 & 0.18 & 0.0 \\
\hline $23 ; 3 ;$ EARTH & Earth backfill at top of shaft & SIIBCEXP & 0.0 & 0.0 & $S I J R B R S A 7^{b}$ & SHRGSSA $7^{\mathrm{b}}$ & 0.32 & $3.10 \times 10^{-8}$ \\
\hline $24 ; 4 ; C L A Y$ RUS & Clay seal in shaft through Rustler Fm & $S H B C E X P^{b}$ & 0.0 & 0.0 & SHRBRSAT" & SHRGSSA $7^{6}$ & 0.24 & $1.96 \times 10^{-9}$ \\
\hline 25; 5; ASPHIALT & Asphalt shaft seal & $S H B C E X P^{6}$ & 0.0 & 0.0 & $S I I R B R S A 7^{b}$ & SHRGSSA $7^{\mathrm{b}}$ & 0.01 & $2.97 \times 10^{-8}$ \\
\hline $26 ; 6 ; \mathrm{CONC}_{-} \mathrm{TI}$ & Concrete shaft seal, $0-400 \mathrm{yr}$ & $S H B C E X P^{\mathrm{b}}$ & 0.0 & 0.0 & SHRBRSA $7^{\circ}$ & SHRGSSA $7^{\circ}$ & 0.05 & $2.64 \times 10^{-9}$ \\
\hline 27: $6 ; \mathrm{CONC}_{-} \mathrm{T} 2$ & Concrete shaft seal, $400-10000 \mathrm{yr}$ & $S H B C E X P^{\mathrm{b}}$ & 0.0 & 0.0 & SIIRBRSA7 & SHRGSSAT & 0.05 & $2.64 \times 10^{-9}$ \\
\hline $28 ; 8 ;\left(L \_M_{-} T\right)$ & Upper Salado clay shan seal, $0-10 \mathrm{yr}$ & $S H B C E X P^{\mathrm{b}}$ & 0.0 & 0.0 & SIIRBRSAT ${ }^{\mathrm{b}}$ & $S H R G S S A T^{\mathrm{b}}$ & 0.24 & $1.81 \times 10^{-9}$ \\
\hline $29 ; 8 ; \mathrm{CL}_{-} \mathrm{M}_{-} \mathrm{T} 2$ & Upper Salado clay shaft seal, $10-25 \mathrm{yr}$ & $S H B C E X P^{b}$ & 0.0 & 0.0 & SIIRBRSA $7^{\mathrm{b}}$ & SHRGSSA $7^{\mathrm{b}}$ & 0.24 & $1.81 \times 10^{-9}$ \\
\hline $30 ; 8 ; \mathrm{CL}_{-} \mathrm{M}_{-} \mathrm{T} 3$ & Upper Salado clay shatt seal, $25-50 \mathrm{yr}$ & $S H B C E X P^{b}$ & 0.0 & 0.0 & $S I I R B R S A 7^{6}$ & SIIRGSSAT & 0.24 & $1.81 \times 10^{-9}$ \\
\hline $31 ; 8 ; \mathrm{CL}^{-} \mathrm{M} 44$ & Upper Salado clay slaft scal, $50-100 \mathrm{yr}$ & $S H B C E X P^{b}$ & 0.0 & 0.0 & SIIRBRSA7 ${ }^{\circ}$ & SHRGSSAT $T^{\mathrm{b}}$ & 0.24 & $1.81 \times 10^{-9}$ \\
\hline $32 ; 8 ; C L_{-} M_{-} T S$ & Upper Salado clay shaft seal, $100-10000 \mathrm{yr}$ & $S H B C E X P^{b}$ & 0.0 & 0.0 & SHRBRSA $7^{\circ}$ & SHRGSSA $7^{\mathrm{b}}$ & 0.24 & $1.81 \times 10^{-9}$ \\
\hline $33 ; 9 ;\left(1, \mathrm{~L}_{-} \mathrm{T}\right)$ & L.ower Salade clay shaft scal, $0-10 \mathrm{yr}$ & $S H B C E X P^{b}$ & 0.0 & 0.0 & SIIRBRSAT' & SHIRGSSA $T^{\mathrm{b}}$ & 0.24 & $1.59 \times 10^{-9}$ \\
\hline
\end{tabular}


Table 1. Parameter Values Used in Representation of Two Phase Flow (continued)

\begin{tabular}{|c|c|c|c|c|c|c|c|c|}
\hline Material: I; R; $N^{\prime}$ & Material Description & $\lambda$ & $a$ & 1 & $s_{b r}$ & $S_{g r}$ & $\phi_{0}$ & $\beta_{f}$ \\
\hline $34: 9):(1,1.12$ & Lower Salado clay shaft seal, $10 \cdot 25 \mathrm{yr}$ & $S H B C E X P^{\mathrm{b}}$ & 0.0 & 0.0 & SHIRBRSAT & SHRGSSA $7^{\circ}$ & 0.24 & $1.59 \times 10^{-9}$ \\
\hline $35: 9: C_{1} 1 . T 3$ & Lower Salado clay shaft seal, $25-50 \mathrm{yr}$ & $S H B C E X P^{h}$ & 0.0 & 0.0 & SHRBRSA $T^{\mathrm{b}}$ & SHRGSSA $7^{\mathrm{b}}$ & 0.24 & $1.59 \times 10^{-9}$ \\
\hline $30 ; 9 ;(1), 1,14$ & Lower Salado clay shaft seal, $50-10000 \mathrm{yr}$ & SIIBCEXP' & 0.0 & 0.0 & SIIRBRSA $7^{\mathrm{b}}$ & SIIRGSSA $7^{\circ}$ & 0.24 & $1.59 \times 10^{-9}$ \\
\hline 37:7:SALT_TI & Crushed salt shan backfill, $0-10 \mathrm{yr}$ & $S H B C E X W^{1 /}$ & 0.0 & 0.0 & SWRBRSA $7^{\mathrm{b}}$ & SHRGSSA $7^{6}$ & 0.05 & $1.60 \times 10^{-9}$ \\
\hline $38 ; 7 ; S \wedge 1 T \div 2$ & Crushed salt shaft backlill, $10-25 \mathrm{yr}$ & $S H B C E X P^{b}$ & 0.0 & 0.0 & $S H: H B R S A 7^{6}$ & SURGSSA $7^{6}$ & 0.05 & $1.60 \times 10^{-9}$ \\
\hline $39 ; 7 ;$ SALT_T3 & Crushed salt shaft backfill, $25-50 \mathrm{yr}$ & $S H B C E X P^{b}$ & 0.0 & 0.0 & SIIRBRSAI & SHRGSSA $7^{b}$ & 0.05 & $1.60 \times 10^{-9}$ \\
\hline 40:7: SALT T4 & Crushed salt shaft backfill, $50-100 \mathrm{yr}$ & SHIBCEXXPh & 0.0 & 0.0 & $S I I R B R S A 7^{\mathrm{b}}$ & SIIRGSSA $7^{\mathrm{b}}$ & 0.05 & $1.60 \times 10^{-9}$ \\
\hline $41 ; 7 ; 5 \wedge 1.1 \_15$ & Crushed salt shaft backfill, $100 \cdot 200 \mathrm{yr}$ & $S H B C E X P^{\mathrm{b}}$ & 0.0 & 0.0 & $S I I R B R S A T^{\natural}$ & SHRGSSA $7^{\mathrm{b}}$ & 0.05 & $1.60 \times 10^{-9}$ \\
\hline $42 ; 7 ;$ SALT..T6 & Crushed salt sluaft backfill, $200-10000 \mathrm{yr}$ & $S H B C E X P^{\mathrm{b}}$ & 0.0 & 0.0 & SIIRBRSA7b & SHRGSSA $7^{\circ}$ & 0.05 & $1.60 \times 10^{-9}$ \\
\hline $43 ; 10 ; C_{L A Y} B O T$ & Lower (bottom) clay shaft seal & $S H B C E X W^{l)}$ & 0.0 & 0.0 & SWIRBRSA & SUIRGSSA $7^{6}$ & 0.24 & $1.59 \times 10^{-9}$ \\
\hline $44 ; 25 ;$ PAN_SEAL. & Pancl scal & 0.94 & 0.50 & -0.346 & 0.2 & 0.2 & 0.075 & $2.64 \times 10^{-9}$ \\
\hline $45 ; 11 ; C_{0 N C}$ MON & Concrete shaft station monolith & $S W B C E X P^{\mathrm{b}}$ & 0.0 & 0.0 & SIIRBRSA $7^{\mathrm{b}}$ & SHRGSSA $7^{\mathrm{b}}$ & 0.05 & $2.64 \times 10^{-9}$ \\
\hline $40 ; 22 ; D R Z_{-} 1$ & Disturbed rock zone & 0.7 & 0.0 & 0.0 & 0.0 & 0.0 & $f(I I A L P O R)^{\mathrm{c}}$ & $0.280054 \times 10^{-8}$ \\
\hline 47: IA; CONC_PLG & Concrete borchole plug & 0.94 & 0.0 & 0.0 & 0.0 & 0.0 & 0.32 & 0.0 \\
\hline $48 ; 113, C ; 1311$, OPEN & "Open" borchole & 0.7 & 0.0 & 0.0 & 0.0 & 0.0 & 0.32 & 0.0 \\
\hline 49; I $I B, C ; B H \_S A N D$ & Sand-filled borehole & 0.94 & 0.0 & 0.0 & 0.0 & 0.0 & 0.32 & 0.0 \\
\hline 50; $10 ; B H 1$ CRIEEP & Sand-tilled borchole after creep closure & 0.94 & 0.0 & 0.0 & 0.0 & 0.0 & 0.32 & 0.00 \\
\hline
\end{tabular}

"Material identilier, where $/$ - integer identifier, $R-$ region in Fig. $1, N \sim$ material name.

b Sec Table 1, Ref. 11.

c See liq. (16).

"See Eq. (18); $\phi_{0}$ can also be delined by an uncertain variable.

- See Eq. (17). 
Table 2. Values Used for Intrinsic Permeability $k$ in Representation of Two-Phase Flow

\begin{tabular}{|c|c|c|c|}
\hline Material: I; R; Nà & $k, \mathrm{~m}^{2}$ & Material: $I ; R ; N^{a}$ & $k, \mathrm{~m}^{2}$ \\
\hline $1 ; 2 ;$ S_HALITE & $10^{x}, x=H A L P R M^{b}$ & $26 ; 6 ; \mathrm{CONC}_{-} \mathrm{T} 1$ & $10^{x}, x=S H P R M C O N^{b}$ \\
\hline $2 ; 22 ; \overline{\mathrm{D} R Z} \_0$ & $9.999999 \times 10^{-18}$ & $27 ; 6 ;$ CONC_T2 & $1.0 \times 10^{-14}$ \\
\hline $3 ; 28 ;$ S_MB139 & $10^{x}, x=A N H P R M^{b}$ & $28 ; 8 ; \mathrm{CL}_{-} \mathrm{M}_{-} \mathrm{T} 1$ & $\begin{array}{l}f(S H P R M C L Y, \\
S H P R M D R Z, H A L P R M)^{\mathrm{c}}\end{array}$ \\
\hline $4 ; 21 ; S_{-}$ANH_AB & $10^{x}, x=A N H P R M^{\mathrm{b}}$ & $29 ; 8 ;$ CL_M_T2 & $\begin{array}{l}f(S H P R M C L Y \\
S H P R M D R Z, H A L P R M)^{\mathrm{c}}\end{array}$ \\
\hline $5 ; 20 ;$ S_MB138 & $10^{x}, x=A N H P R M^{b}$ & $30 ; 8 ;$ CL_M_T3 & $\begin{array}{l}\text { f(SHPRMCLY, } \\
\text { SHPRMDRZ, HALPRM) }\end{array}$ \\
\hline $6 ; 23 ;$ CAVTTY_1 $_{1}$ & $1.0 \times 10^{-10}$ & $31 ; 8 ;$ CL_M_T4 & $\begin{array}{l}\text { fSHPRMCLY, } \\
\text { SHPRMDRZ, HALPRM })^{\mathrm{c}}\end{array}$ \\
\hline $7 ; 24 ; \mathrm{CAVTTY} 2$ & $1.0 \times 10^{-10}$ & $32 ; 8 ; C L \_M \_T 5$ & $\begin{array}{l}f(S H P R M C L Y, \\
S H P R M D R Z, H A L P R M)^{\mathrm{C}}\end{array}$ \\
\hline $8 ; 26 ;$ CAVTTY_3 $_{2}$ & $1.0 \times 10^{-10}$ & $33 ; 9 ;$ CL_L_T1 & $10^{x}, x=S H P R M C L Y^{\circ}$ \\
\hline $9 ; 27 ;$ CAVITY_4 & $1.0 \times 10^{-10}$ & $34 ; 9 ;$ CL_L_T2 & $\begin{array}{l}f(S H P R M C L Y, \\
S H P R M D R Z, H A L P R M)^{\complement}\end{array}$ \\
\hline 10; 29;IMPERM_Z & $9.999999 \times 10^{-36}$ & $35 ; 9 ;$ CL_L_T3 & $\begin{array}{l}\text { fSHPRMCLY, } \\
\text { SHPRMDRZ, HALPRM })^{\mathrm{C}}\end{array}$ \\
\hline $11 ; 30 ;$ CASTILER & $10^{x}, x=B P P R M^{b}$ & $36 ; 9 ; C_{-} L$ _T4 & $\begin{array}{l}f(S H P R M C L Y \\
\text { SHPRMDRZ, HALPRM }\end{array}$ \\
\hline 12; 23; WAS_AREA & $1.702158 \times 10^{-13}$ & $37 ; 7 ; S_{A L T}$ T1 & $\begin{array}{l}f(S H P R M D R Z, \\
S H P R M H A L, H A L P R M)^{c}\end{array}$ \\
\hline 13; 24; REPOSIT & $1.702158 \times 10^{-13}$ & $38 ; 7 ;$ SALT_T2 & $\begin{array}{l}f(S H P R M D R Z, \\
\text { SHPRMHAL, HALPRM })^{c}\end{array}$ \\
\hline $14 ; 18 ;$ UNNAMED & $9.999999 \times 10^{-36}$ & $39 ; 7 ;$ SALT_T3 & $\begin{array}{l}\text { f(SHPRMDRZ, } \\
\text { SHPRMHAL, HALPRM })^{\circ}\end{array}$ \\
\hline $15 ; 17 ;$ CULEBRA & $2.098938 \times 10^{-14}$ & $40 ; 7$; SALT_T4 & $\begin{array}{l}\text { f(SHPRMDRZ, } \\
\text { SHPRMHAL, HALPRM })^{\circ}\end{array}$ \\
\hline 16; 16; TAMARISK & $9.999999 \times 10^{-36}$ & $41 ; 7$;SALT_T5 & $\begin{array}{l}f(S H P R M D R Z, \\
\text { SHPRMHAL, HALPRM })^{\mathrm{c}}\end{array}$ \\
\hline $17 ; 15 ;$ MAGENTA & $6.309576 \times 10^{-16}$ & $42 ; 7 ;$ SALT_T6 & $\begin{array}{l}f(S H P R M D R Z, \\
S H P R M H A L, H A L P R M)^{\mathrm{c}}\end{array}$ \\
\hline 18; 14; FORTYNIN & $9.999999 \times 10^{-36}$ & $43 ; 10 ;$ CLAY_BOT & $10^{x}, x=S H P R M C L Y^{\mathrm{b}}$ \\
\hline 19; 13; DEWYLAKE & $5.011881 \times 10^{-17}$ & $44 ; 25 ;$ PAN_SEAL & $1.0 \times 10^{-15}$ \\
\hline $20 ; 12 ;$ SANTAROS & $1.0 \times 10^{-10}$ & $45 ; 11 ; \mathrm{CONC}_{-} \mathrm{MON}$ & $1.0 \times 10^{-14}$ \\
\hline $21 ; 26 ;$ OPS_AREA & $1.0 \times 10^{-11}$ & $46 ; 22 ; D_{R} Z_{-}{ }^{-}$ & $1.0 \times 10^{-15}$ \\
\hline $22 ; 27 ;$ EXP_AREA & $1.0 \times 10^{-11}$ & $47 ; 1 \mathrm{~A} ; \mathrm{CONC}-\mathrm{PLG}$ & $5.000339 \times 10^{-17}$ \\
\hline $23 ; 3 ;$ EARTH & $1.0 \times 10^{-14}$ & $48 ; 1 \mathrm{~B}, \mathrm{C} ; \mathrm{BH} \_\mathrm{OPEN}$ & $1.0 \times 10^{-9}$ \\
\hline $\begin{array}{l}24 ; 4 ; \text { CLAY RUS } \\
25 ; 5 ; \text { ASPHALT }\end{array}$ & $\begin{array}{l}10^{x}, x=S H P R M C L Y^{b} \\
f(S H P R M A S P)^{\mathrm{c}}\end{array}$ & $\begin{array}{l}\text { 49: 1A.B,C;BH_SAND } \\
\text { 50;1C:BH_CREEP }\end{array}$ & $\begin{array}{l}10^{\mathrm{x}}, x=B H P R M^{\mathrm{b}} \\
10^{x} / 10, x=B H P R M^{\mathrm{b}}\end{array}$ \\
\hline
\end{tabular}

\footnotetext{
a Material identifier, where $I \sim$ integer identifier. $R \sim$ region in Fig. $1, N$ material name. See Table $I$ for more detailed material descriptions.

b See Table 1, Ref 11 .

c See Eqs. (35). (36).
} 
Table 3. Models Used in Representation of Relative Permeability and Capillary Pressure for TwoPhase Flow

\begin{tabular}{|c|c|c|c|c|c|}
\hline Material: $I ; R ; N^{a}$ & $\begin{array}{c}\text { Relative } \\
\text { Permeability }\end{array}$ & $\begin{array}{l}\text { Capillary } \\
\text { Pressure }^{\mathfrak{c}}\end{array}$ & Material: $\mathrm{I} ; \mathrm{R} ; \mathrm{N}^{\mathrm{a}}$ & $\begin{array}{c}\text { Relative } \\
\text { Permeability }\end{array}$ & $\begin{array}{l}\text { Capillary } \\
\text { Pressure }^{\circ}\end{array}$ \\
\hline $1 ; 2 ;$ S_HALITE & 4 & 2 & $26 ; 6 ;$ CONC_Tl $_{1}$ & 4 & 1 \\
\hline $2 ; 22 ; \bar{D} R Z \_0$ & 4 & 1 & $27 ; 6 ; \mathrm{CONC}_{-} \mathrm{T} 2$ & 4 & 1 \\
\hline $3 ; 28 ; S_{-} M \bar{B} 139$ & $A N H B C V G P$ & 2 & $28 ; 8 ; \mathrm{CL}_{-} \mathrm{M}_{-} \mathrm{T} 1$ & 4 & 1 \\
\hline $4 ; 21 ; \mathrm{S}_{-} \mathrm{ANH} \_\mathrm{AB}$ & $A N H B C V G P$ & 2 & $29 ; 8 ; \mathrm{CL}_{-} \mathrm{M}_{-}^{-} \mathrm{T} 2$ & 4 & 1 \\
\hline $5 ; 20 ; S_{-} M B 138$ & $A N H B C V G P$ & 2 & $30 ; 8 ; \mathrm{CL}_{-} \mathrm{M}-\mathrm{T} 3$ & 4 & 1 \\
\hline $6 ; 23 ;$ CAVITY_1 $_{1}$ & 4 & 1 & $31 ; 8 ; \mathrm{CL}_{-} \mathrm{M}$ T4 & 4 & 1 \\
\hline $7 ; 24 ;$ CAVITY_2 $_{2}^{-2}$ & 4 & 1 & $32 ; 8 ; \mathrm{CL}_{-} \mathrm{M}_{-} \mathrm{T} 5$ & 4 & 1 \\
\hline $8 ; 26 ;$ CAVITY_3 $^{-3}$ & 4 & 1 & $33 ; 9 ; \mathrm{CL}_{-} \mathrm{L}-\mathrm{T} 1$ & 4 & 1 \\
\hline $9 ; 27 ;$ CAVITY_4 & 4 & 1 & $34 ; 9 ; \mathrm{CL} L L_{-} \mathrm{T} 2$ & 4 & 1 \\
\hline $10 ; 29 ;$ IMPERM_Z_Z & 4 & 1 & $35 ; 9 ; \mathrm{CL}_{-} \mathrm{L}-\mathrm{T} 3$ & 4 & 1 \\
\hline $11 ; 30 ;$ CASTILER & 4 & 2 & $36 ; 9 ; \mathrm{CL}^{-} \mathrm{L} 4$ & 4 & 1 \\
\hline $12 ; 23 ;$ WAS_AREA & 4 & 1 & $37 ; 7 ;$ SALT T1 & 4 & 1 \\
\hline $13 ; 24 ;$ REPOSIT & 4 & 1 & $38 ; 7 ;$ SALT_T2 & 4 & 1 \\
\hline $14 ; 18$; UNNAMED & 4 & 1 & $39 ; 7 ;$ SALT T3 & 4 & 1 \\
\hline $15 ; 17 ;$ CULEBRA & 4 & 2 & $40 ; 7 ;$ SALT_T4 & 4 & 1 \\
\hline $16 ; 16$; TAMARISK & 4 & 1 & $41 ; 7 ;$ SALT_T5 & 4 & 1 \\
\hline 17; 15; MAGENTA & 4 & 2 & $42 ; 7 ;$ SALT_T6 $_{-}^{-}$ & 4 & 1 \\
\hline $18 ; 14 ;$ FORTYNN & 4 & 1 & $43 ; 10 ;$ CLAY $\bar{Y}$ BOT & 4 & 1 \\
\hline 19; 13; DEWYLAKE & 4 & 1 & $44 ; 25 ;$ PAN_SEAL & 4 & 2 \\
\hline $20 ; 12 ;$ SANTAROS & 4 & 1 & $45 ; 11 ; \mathrm{CONC}_{-} \mathrm{MON}$ & 4 & 1 \\
\hline $21 ; 26 ;$ OPS_AREA & 4 & 1 & $46 ; 22 ; \mathrm{DRZ} 1$ & 4 & 1 \\
\hline $22 ; 27 ;$ EXP_AREA & 4 & 1 & $47 ; 1 \mathrm{~A} ; \mathrm{CONC}$ PLG & 4 & 1 \\
\hline $23 ; 3 ;$ EARTH & 4 & 1 & $48 ; 1 \mathrm{~B}, \mathrm{C} ; \mathrm{BH} \_\mathrm{OPEN}$ & 5 & -1 \\
\hline $24 ; 4 ;$ CLAY_RUS & 4 & 1 & $49 ; 1 \mathrm{~A}, \mathrm{~B}, \mathrm{C} ; \mathrm{BH} \_\mathrm{SAND}$ & 4 & 1 \\
\hline $25 ; 5 ;$ ASPHALT & 4 & 1 & S0; 1C;BH_CREEP & 4 & 1 \\
\hline
\end{tabular}

a Material identifier, where $I-$ integer identifier, $R$ - region in Fig. $1, N \sim$ material name. See Table 1 for more detailed material descriptions.

b Relative permeability model, where 1 van Genuchten-Parker model (Eqs. 19 - 21), 4 - Brooks-Corey model (Eqs. 10 - 12), $5 \sim$ linear model (Eq. 22), and ANHBCVGP use of Brooks-Corey or van Genuchten-Parker model treated as a subjective uncernainty (see Table i, Ref. 11).

c Capillary pressure model, where $1 \sim p_{C}=0 \mathrm{~Pa}, 2 \sim p_{C}$ bounded above by $1 \times 10^{8} \mathrm{~Pa}$ as $S_{b}$ approaches $S_{b r}$ 
Table 4. Initial Conditions for $p_{b}$ and $S_{g}$ at $(x, y,-5 \mathrm{yr})$ and Reset Conditions ${ }^{\mathrm{a}}$ for $p_{b}$ and $S_{g}$ at $(x, y, 0 \mathrm{yr})$

Initial Conditions: Brine Pressure $p_{b}(x, y,-5$ yr $)$

1) Rustler Fm and overlying units (except in the shaft). Modeled as horizontal with spatially constant initial pressure in each layer (see Fig. 1 and Table 2).

\begin{tabular}{ccccc}
\hline $\begin{array}{c}\text { Mesh Layer } \\
\text { (Fig. 1) }\end{array}$ & $\begin{array}{c}\text { Material } \\
\text { Index } \\
\text { (Table 2) }\end{array}$ & $\begin{array}{c}\text { Region } \\
\text { Index } \\
\text { (Fig. 1) }\end{array}$ & Name & $p_{b}(x, y,-5), \mathrm{Pa}$ \\
\hline 31 & 20 & 12 & Santa Rosa Fm & $1.013250 \times 10^{5}$ \\
30 & 20 & 12 & Santa Rosa Fm & $1.013250 \times 10^{5}$ \\
29 & 19 & 13 & Dewey Lake & $1.013250 \times 10^{5}$ \\
28 & 19 & 13 & Dewey Lake & $7.345482 \times 10^{5}$ \\
27 & 18 & 14 & Forty-Niner & $1.471170 \times 10^{6}$ \\
26 & 17 & 15 & Magenta & $9.170000 \times 10^{5}$ \\
25 & 16 & 16 & Tamarisk & $1.824205 \times 10^{6}$ \\
24 & 15 & 17 & Culebra & $8.220000 \times 10^{5}$ \\
23 & 14 & 18 & Unnamed & $2.279613 \times 10^{6}$ \\
\hline
\end{tabular}

2) Salado Fm (Mesh Layers 3 - 22) The Salado is assumed to dip uniformly $\theta=1^{\circ}$ downward from north to south. Except in repository excavations and shaft, brine is assumed initially (i.e., at $-5 \mathrm{yr}$ ) to be in hydrostatic equilibrium relative to an uncertain initial pressure $p_{b, r e f}$ (see $S A L P R E S$ in Table 1 , Ref. 11) at a reference point located at center of shaft at elevation of midpoint of MB 139 (i.e., at $\left.\left(x_{r e f}, y_{r e f}\right)=(23664.9 \mathrm{~m}, 379.685 \mathrm{~m})\right)$, which is the center of cell 644 in Fig. 3), which gives rise to the condition

$p_{b}(x, y,-5)=p_{b 0}+\left(1 / \beta_{b}\right) \ln \left[\rho_{b}(x, y,-5) / \rho_{b 0}\right]$

where

$\rho_{b}(x, y,-5)=\frac{1}{g \beta_{b}\left[y_{e}-\Phi\left(x_{r e f}, y_{r e f},-5\right)+\frac{1}{g \beta_{b} \rho_{b 0}}\right]}$

$\Phi\left(x_{r e f}, y_{r e f},-5\right)=y_{r e f}+\frac{1}{g \beta_{b}}\left[\frac{1}{\rho_{b 0}}-\frac{1}{\rho_{b}\left(x_{\text {ref }}, y_{\text {ref }},-5\right)}\right]$

$\rho_{b}\left(x_{r e f}, y_{r e f},-5\right)=\rho_{b 0} \exp \left[-\beta_{b}\left(p_{b, r e f}-p_{b 0}\right)\right]$

$y_{e}=y_{r e f}+h(x, y)=y_{r e f}+\left(x-x_{r e f}\right) \sin \theta+\left(y-y_{r e f}\right) \cos \theta \quad$ (See Eq. (9))

$\rho_{b 0}=1220 \mathrm{~kg} / \mathrm{m}^{3}, \beta_{b}=3.1 \times 10^{-10} \mathrm{~Pa}^{-1}, g=9.79 \mathrm{~m} / \mathrm{s}^{2}, p_{b 0}=1.01325 \times 10^{5} \mathrm{~Pa}$

3) Castile Fm (Mesh Layers 1 and 2). The Castile is modeled as horizontal, and initial brine pressure is spatially constant in each layer. except that the brine reservoir is treated as a different material from rest of Castile and has a different initial pressure. Specifically, 
Table 4. Initial Conditions for $p_{b}$ and $S_{g}$ at $(x, y,-5 \mathrm{yr})$ and Reset Conditions ${ }^{\mathrm{a}}$ for $p_{b}$ and $S_{\mathrm{g}}$ at $(x, y, 0 \mathrm{yr})$ (continued)

$$
\begin{aligned}
p_{b}(x, y,-5) & =1.55 \times 10^{7} \mathrm{~Pa} & & \text { in region } 29 \\
& =\text { BPINTPRS } & & \text { in region 30; see Table 1, Ref. } 11
\end{aligned}
$$

4) Shaft and repository excavations (Materials $6-9) \cdot p_{b}(x, y,-5)=1.01325 \times 10^{5} \mathrm{~Pa}$.

Reset Conditions: Brine Pressure $p_{b}(x, y, 0 \mathrm{yr})$

44, 45; Regions 3, 6-11, 23 - 27)

Initial Conditions: Gas Saturation $S_{g}(x, y,-5 \mathrm{yr})$

$S_{g}(x, y,-5)=1-S_{b r}=0.916 \quad$ Santa Rosa Fm above water table (Mesh Layer $\left.30-31\right)$

$=1-S_{b r}=0.916$ Dewey Lake Redbeds above water table (Mesh Layer 29)

$=0 \quad$ Dewey Lake Redbeds below water table (Mesh Layer 28)

$=0 \quad$ Rustler, Salado, and Castile Fms below water table (Mesh Layers $1-27)$

$=1 \times 10^{-7} \quad$ Shaft and Panel Closures [Except Asphalt (Material 25; Region 5)]

(Regions 3, 4, 6-11, 23-27, 44)

$=1.0 \quad$ Asphalt Shaft Seal (Material 25; Region 5)

$=1.0$ Waste Panel Repository, Operations Region, Experimental Area (Materials 12, 13, 21, 22; Regions 23, 24, 26, 27)

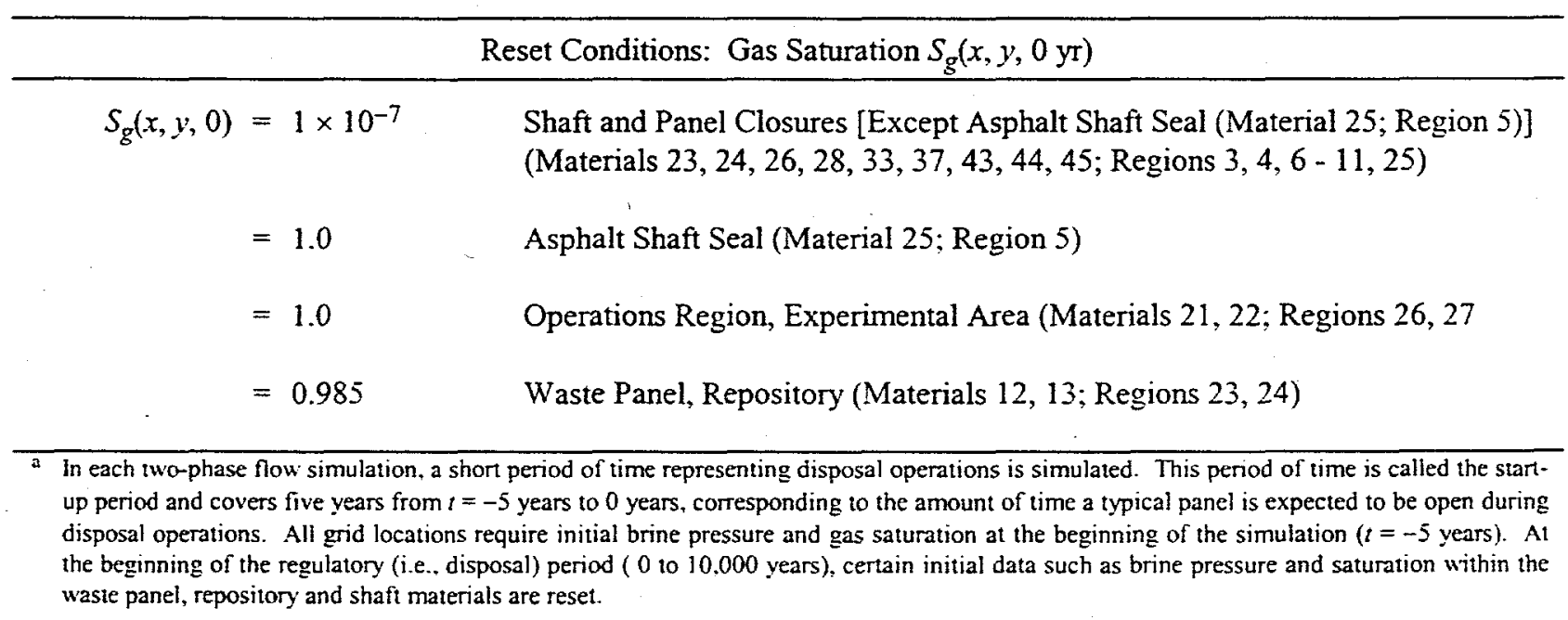


Table 5. Treatment of Transient Permeability Associated with Shaft Seals

\begin{tabular}{lccc}
\hline \multicolumn{1}{c}{ Material } & $\begin{array}{c}\text { Transient Seal } \\
\text { Permeability }\end{array}$ & DRZ Present & $\begin{array}{c}\text { Transient DRZ } \\
\text { Permeability }\end{array}$ \\
\hline Earthen Fill (region 3, Fig. 1) & No & No & N/A \\
Rustler Clay Column (region 4, Fig. 1) & No & No & N/A \\
Asphalt Column (region 5, Fig. 1) & No & Yes & No \\
Salado Concretes (region 6, Fig. 1) & Yes & No & N/A \\
Salado Clay Columns (regions 8, 9, Fig. 1) & No & Yes & Yes \\
Salado Salt Colurm (region 7, Fig. 1) & Yes & Yes & Yes \\
\hline
\end{tabular}

Table 6. Times at Which Permeabilities are Changed for Shaft Seal and DRZ Materials

\begin{tabular}{lc}
\hline \multicolumn{1}{c}{ Material } & Permeability Changes \\
\hline All Concretes (region 6, Fig. 1) & 400 years \\
DRZ, Upper Salado Clay Column (region 8, Fig. 1; DRZ-2 in Fig. 5) & $10,25,50 \& 100$ years \\
Salado Salt Column (region 7, Fig. 1) & $50,100 \& 200$ years \\
DRZ, Salado Salt Column (region 7, Fig. 1; DRZ-3 in Fig. 5) & $10 \& 25$ years \\
DRZ, Lower Salado Clay Column (region 8, Fig. 1; DRZ-4 in Fig. 5) & $10,25 \& 50$ years \\
\hline
\end{tabular}

Table 7. Normalized Radius for DRZ Associated with Individual Shaft Components (after Ref. 30)

\begin{tabular}{llllll}
\hline & \multicolumn{5}{c}{ DRZ Extent: Normalized Radius $\left(r_{\text {out }} / r_{\text {in }}\right)$} \\
\cline { 2 - 6 } Seal Material and Associated DRZ Zone & \multicolumn{3}{c}{ Time Referenced to Instantaneous Emplacement of Seal Materials } \\
\cline { 2 - 6 } & 0 years & 10 years & 25 years & 50 years & 100 years \\
\hline $\begin{array}{c}\text { Asphalt Column } \\
\quad \text { (region 5, Fig. 1; DRZ-1, Fig. 5) }\end{array}$ & 1.629 & 1.629 & 1.629 & 1.629 & 1.629 \\
$\begin{array}{c}\text { Upper Salado Clay } \\
\quad \text { (region 8, Fig. 1; DRZ-2, Fig. 5) }\end{array}$ & 1.709 & 1.469 & 1.283 & 1.107 & 1.000 \\
$\begin{array}{c}\text { Reconsolidated Salt } \\
\quad \text { (region 7, Fig. 1; DRZ-3, Fig. 5) }\end{array}$ & 1.814 & 1.110 & 1.000 & 1.000 & 1.000 \\
$\begin{array}{c}\text { Lower Salado Clay } \\
\quad \text { (region 7, Fig. 1; DRZ-4, Fig. 5) }\end{array}$ & 1.858 & 1.162 & 1.002 & 1.000 & 1.000 \\
\hline
\end{tabular}


Table 8. Permeabilities Used with BRAGFLO Calculations for Drilling Intrusions Through the Repository (see materials 47, 48, 49, 50 in Table 2)

\begin{tabular}{|c|c|}
\hline Time After Intrusion & Assigned Permeabilities \\
\hline $0-200 \mathrm{yr}$ & $\begin{array}{l}\text { Concrete plugs assumed to be emplaced at the Santa Rosa Fm (i.e., a surface plug with } \\
\text { a length of } 15.76 \mathrm{~m} \text {; corresponds to grid cells } 905,937 \mathrm{in} \mathrm{Fig.} \mathrm{3)} \mathrm{and} \mathrm{the} \mathrm{Unnamed} \\
\mathrm{Mbr} \text { of the Rustler Fm (i.e., a plug at top of Salado Fm with a length of } 36 \mathrm{~m} \text {; } \\
\text { corresponds to grid cell } 681 \mathrm{in} \text { Fig. 3). Concrete plugs assumed to have a permeability } \\
\text { of } k=5 \times 10^{-17} \mathrm{~m}^{2} \text {; remainder of borehole assumed to have a permeability of } 1 \times 10^{-9} \\
\mathrm{~m}^{2} \text {. }\end{array}$ \\
\hline $200-1200$ y & $\begin{array}{l}\text { Concrete plugs are assumed to fail after } 200 \mathrm{yr}^{43} \text { and entire borehole is assigned a } \\
\text { permeability typical of silty sand, i.e., } k=10^{x} \mathrm{~m}^{2}, x=B H P R M \text {, where BHPRM is an } \\
\text { uncertain input to the analysis (see Table 1, Ref. } 11 \text { ). }\end{array}$ \\
\hline$>1200 \mathrm{yr}$ & $\begin{array}{l}\text { Permeability reduced by one order of magnitude in Salado Fm beneath repository due } \\
\text { to creep closure of borehole } \mathrm{e}^{50} \text { (i.e., } k=10^{x} / 10, x=B H P R M \text {, in grid cells } 1010,985 \text {, } \\
12,45,78,439,453 \text { of Fig. } 3 \text { ). No changes are made within and above the lower DRZ. }\end{array}$ \\
\hline
\end{tabular}

Table 9. Boundary Value Conditions for $p_{g}$ and $p_{b}$, with the Imposed Conditions Resulting in No Flow Across the System Boundaries

Boundaries below $(y=0 \mathrm{~m})$ and above $(y=1039 \mathrm{~m})^{\mathrm{a}}$ system for $0 \leq x \leq 46630 \mathrm{~m}$ and $-5 \mathrm{yr} \leq t$

\begin{tabular}{ll}
\hline$\left.\left(\nabla p_{g}+\rho_{g} g \nabla h\right)\right|_{(x, y, t)} \bullet \mathrm{j}=0 \mathrm{~Pa} / \mathrm{m}$ & $\begin{array}{l}\text { no gas flow condition } \\
\text { no brine flow condition }\end{array}$ \\
\hline \multicolumn{1}{c}{ Boundaries at left $(x=0 \mathrm{~m})$ and right $(x=46630 \mathrm{~m})$ of system for $0 \leq y \leq 1039 \mathrm{~m}$ and $-5 \mathrm{yr} \leq t$} \\
\hline$\left.\left(\nabla p_{g}+\rho_{g} g \nabla h\right)\right|_{(x, y, t)} \bullet \mathbf{i}=0 \mathrm{~Pa} / \mathrm{m}$ & no gas flow condition \\
$\left.\left(\nabla p_{b}+\rho_{b} g \nabla h\right)\right|_{(x, y, t)} \bullet \mathbf{i}=0 \mathrm{~Pa} / \mathrm{m}$ & no brine flow condition \\
\hline
\end{tabular}

${ }^{a}$ Height of grid for disturbed (i.e., El, E2) calculations; a grid with a height of $911 \mathrm{~m}$ used for undisturbed (i.e., E0) calculations.

Table 10. Auxiliary Dirichlet Conditions for $p_{b}$ and $S_{g}$

\begin{tabular}{lc}
\hline & Surface Grid Blocks \\
\hline$S_{\mathrm{g}}(i, j, t)=0.08363$ & $i=1,2, \ldots, 33, j=31,-5 \mathrm{yr} \leq t$ \\
$p_{b}(i, j, t)=1.01 \times 10^{5} \mathrm{~Pa}$ & $i=1,2, \ldots, 33, j=31,-5 \mathrm{yr} \leq t$ \\
\hline & Culebra and Magenta Far Field \\
\hline$p_{b}(i, 24, t)=8.22 \times 10^{5} \mathrm{~Pa}$ & $i=1$ and $33, j=24,-5 \mathrm{yr} \leq t$ (Culebra) \\
$p_{b}(i, 26, t)=9.17 \times 10^{5} \mathrm{~Pa}$ & $i=1$ and $33, j=26,-5 \mathrm{yr} \leq t$ (Magenta) \\
\hline
\end{tabular}

